\title{
Estimation of the total magnetization direction of approximately spherical bodies
}

\author{
V. C. Oliveira Jr. ${ }^{1}$, D. P. Sales ${ }^{1}$, V. C. F. Barbosa ${ }^{1}$, and L. Uieda ${ }^{1,2}$ \\ ${ }^{1}$ Observatório Nacional, Rio de Janeiro, Brazil \\ ${ }^{2}$ Universidade do Estado do Rio de Janeiro, Rio de Janeiro, Brazil \\ Correspondence to: V. C. Oliveira Jr. (vandscoelho@gmail.com) \\ Received: 5 August 2014 - Published in Nonlin. Processes Geophys. Discuss.: 5 September 2014 \\ Revised: 12 December 2014 - Accepted: 7 April 2015 - Published: 24 April 2015
}

\begin{abstract}
We have developed a fast total-field anomaly inversion to estimate the magnetization direction of multiple sources with approximately spherical shapes and known centres. Our method is an overdetermined inverse problem that can be applied to interpret multiple sources with different but homogeneous magnetization directions. It requires neither the prior computation of any transformation-like reduction to the pole nor the use of regularly spaced data on a horizontal grid. The method contains flexibility to be implemented as a linear or non-linear inverse problem, which results, respectively, in a least-squares or robust estimate of the components of the magnetization vector of the sources. Applications to synthetic data show the robustness of our method against interfering anomalies and errors in the location of the sources' centre. Besides, we show the feasibility of applying the upward continuation to interpret non-spherical sources. Applications to field data over the Goiás alkaline province (GAP), Brazil, show the good performance of our method in estimating geologically meaningful magnetization directions. The results obtained for a region of the GAP, near to the alkaline complex of Diorama, suggest the presence of non-outcropping sources marked by strong remanent magnetization with inclination and declination close to -70.35 and $-19.81^{\circ}$, respectively. This estimated magnetization direction leads to predominantly positive reduced-to-the-pole anomalies, even for other region of the GAP, in the alkaline complex of Montes Claros de Goiás. These results show that the non-outcropping sources near to the alkaline complex of Diorama have almost the same magnetization direction of those ones in the alkaline complex of Montes Claros de Goiás, strongly suggesting that these sources have been emplaced in the crust within almost the same geological time interval.
\end{abstract}

\section{Introduction}

The magnetic method is one of the oldest geophysical techniques and plays an important role in mineral and petroleum exploration. This method underwent great progress after the advent of magnetometers properly developed for airborne surveys. Nowadays, the combination of modern satellite positioning systems and improvements in instrumentation and platform compensation makes the aeromagnetic survey one of the most important data acquisition techniques due to the ability to cover large areas in a relatively short period of time (Blakely, 1996; Nabighian et al., 2005). The main applications of the magnetic method are (i) estimating the average depth of the basement relief, (ii) mapping geological faults and abrupt lithological contacts, (iii) defining the limits of mineral targets, (iv) determining the location of geological bodies like salt domes in sediments and (v) identifying geological oil and gas traps. From the physical point of view, all these geological scenarios can be associated with a magnetization distribution produced by magnetized rocks in the subsurface. These magnetized rocks are the magnetic sources producing a magnetic induction that can be measured on the Earth's surface or near to it. This magnetic induction causes local differences between the measured data and the magnetic induction predicted by global models describing the geomagnetic field. By isolating these local deviations, the interpreter can determine the magnetic induction produced by the magnetic sources making up the exploration targets.

The total field is the most common magnetic data measured in a survey. It is defined as the Euclidean norm of the magnetic induction produced by all surrounding magnetic sources. After removing the Euclidean norm of the magnetic induction predicted by a global model describing 
the geomagnetic field and correcting the wide range of undesirable artefacts affecting the data, the result is a scalar quantity denominated total-field anomaly. By using the totalfield anomalies, the geophysicist can characterize the magnetic sources in the subsurface and then better define exploration targets (Telford et al., 1990; Blakely, 1996). Several widely used techniques for interpreting total-field anomalies require correct knowledge of the magnetization direction of the sources. Among these techniques, we emphasize the reduction to the pole (Baranov, 1957; Baranov and Naudy, 1964; Silva, 1986), the pseudo-gravity transformation (Baranov, 1957) and the amplitude of the analytic signal (Nabighian, 1972, 1974, 1984; Li, 2006). Besides, several widely used magnetic inversion methods for estimating the distribution of the magnetization-intensity contrasts in the subsurface also require knowledge of the correct magnetization direction ( $\mathrm{Li}$ and Oldenburg, 1996; Pilkington, 1997; Portniaguine and Zhdanov, 1999, 2002; Barbosa and Silva, 2006). Several methods for determining the magnetization direction of the sources have been developed due to its great importance in interpreting total-field anomalies. Recently, Clark (2014) presented an outstanding and comprehensive review of methods that determine the remanent and total magnetizations of magnetic sources. Here, we present only those ones related to our work.

We divide the methods for retrieving the magnetization direction into two groups. The first one comprises methods that do not impose strong constraints on the shape of the sources. Fedi et al. (1994), for example, accomplished successive reductions to the pole (RTPs) in the wave-number domain by using different tentative magnetization directions. Among this set of RTP anomalies, these authors choose that one whose amplitude of the negative part is minimum. Since this method uses a wave-number approach, it requires that the total-field anomaly be regularly spaced on a horizontal grid with constant height to achieve the computational efficiency of the FFT. Besides, it is known that the RTP in the wave-number domain is unstable at low latitudes and cannot be applied for interpreting total-field anomalies produced by magnetic sources with different magnetization directions. Medeiros and Silva (1995) used the source moments up to second order derived from the multi-pole expansion of the magnetic potential for estimating the magnetization direction and the spatial orientation of a magnetic source. Although this method does not strongly constrain the source's shape, it presumes that the magnetic source has three orthogonal planes of symmetry intersecting each other at the centre of the source. It is also presumed that the source is far from the observation points. Phillips (2005) proposed a method based on the numerical evaluation of the integrals developed by Helbig (1963) for estimating the magnetization direction and the location of multiple magnetic sources from their firstorder magnetic moments. Phillips (2005) stresses that the method is useful for rapid analysis of gridded magnetic data and works best for isolated and compact sources and largely fails for horizontally elongated sources. Tontini and Pedersen (2008) extended this method for using the magnetic moments up to second order to obtain additional information about the horizontal and vertical positions of the centre of the magnetization distribution. Dannemiller and Li (2006) extended the method proposed by Roest and Pilkington (1993), who tackled total-field anomalies produced by generalized 2-D sources, to estimate the magnetization direction of 3-D sources by using the correlation between the vertical gradient and the total gradient of the RTP anomaly obtained through a set of trial directions. These authors stressed that the method assumes that the total-field anomaly is produced by a set of 3-D causative bodies with the same magnetization direction and not by multiple sources with different magnetization directions. A similar method was proposed by Gerovska et al. (2009) based on the comparison between the RTP anomaly and the total magnitude anomaly. Lelièvre and Oldenburg (2009) developed a very flexible method for estimating the magnetization vector distribution in complex geological scenarios. This method discretizes the subsurface of the Earth into a grid of 3-D prisms and estimates the three components (in Cartesian or spherical coordinates) of the magnetization vector of each cell by imposing strong constraints on the solution to deal with the non-uniqueness. Recently, Ellis et al. (2012) presented a similar method to interpret magnetic data in mineral exploration surveys.

The second group of methods to estimate the magnetization direction of the sources assumes knowledge of the shape of the source. The methods belonging to this group have led to a few published papers. Bhattacharyya (1966), for example, proposed an iterative method for determining the magnetization of a uniformly magnetized rectangular prism. The performance of this method is highly dependent on the correct position of the centre and on the determination of the major and minor axes of the body. Emilia and Massey (1974) developed an iterative method for estimating the vertical magnetization distribution of seamounts. This method approximates the seamounts by vertically juxtaposed right prisms with polygonal horizontal cross sections, which have the same magnetization direction and different magnetization intensities. Parker et al. (1987) also developed a method for estimating the magnetization direction of seamounts. This method was formulated as an optimization problem, named semi-norm minimization, to allow estimation of a magnetization distribution that is as close as possible to the uniform distribution. However, in practical applications, this constraint may yield a poor data fit. Finally, Kubota and Uchiyama (2005) discretized the seamount volume as a grid of juxtaposed right rectangular prisms and estimated the Cartesian components of the magnetization vector of each prism.

In this work, we present a computationally efficient method for inverting the total-field anomaly produced by multiple sources with approximately spherical shapes to estimate their magnetization directions. We assume sources with known centres, which can be provided by Euler decon- 
volution, for example. The proposed method is part of the group of methods imposing assumptions about the shape of the magnetic sources. This assumption about the underlying sources is able to reduce the non-uniqueness of the problem to a point that regularization or constraints are not required. Our method can be applied for estimating the average magnetization direction of multiple sources. It requires neither that all sources have the same magnetization direction nor the use of regularly spaced data on a horizontal grid. Besides, our method also contains flexibility to be implemented in two different numerical approaches. The first one minimizes an L2norm, resulting in a linear inverse problem to obtain a leastsquares estimate. The second approach comprises the iterative minimization of an L1-norm, resulting in a non-linear inverse problem to obtain a robust estimate. Applications to synthetic data show the robustness of our method against interfering anomalies and errors in the location of the sources' centres. Additionally, we show how the upward continuation can be used to make possible the application of our method to interpret non-spherical sources. Applications to field data over the Goiás alkaline province (GAP), Brazil, show the good performance of the proposed method in estimating geologically meaningful magnetization directions. The obtained results over a region of the GAP, near to the alkaline complex of Diorama, suggest the presence of non-outcropping sources with strong remanent magnetization, corroborating previous works. The estimated inclinations and declinations are close to -70.35 and $-19.81^{\circ}$, respectively.

\section{Methodology}

\subsection{Parameterization and forward problem}

Let $\Delta \boldsymbol{T}^{\mathrm{o}}$ be the observed data vector, whose $i$ th element $\Delta T_{i}^{\mathrm{o}}, i=1, \ldots, N$, is the total-field anomaly measured at the position $\left(x_{i}, y_{i}, z_{i}\right)$ (black dots in Fig. 1). In this Cartesian coordinate system, $x$ points to the geographic north, $y$ points east and $z$ points downward. In general, the totalfield anomaly is produced by a distribution of magnetization which is anomalous with respect to the mean induced magnetization of the crust. Mathematically, $\Delta T_{i}^{\mathrm{o}}$ can be written as

$$
\Delta T_{i}^{\mathrm{o}}=\left\|\boldsymbol{T}_{i}\right\|-\left\|\boldsymbol{F}_{i}\right\|,
$$

where $\|\cdot\|$ indicates the Euclidean norm, $\boldsymbol{F}_{i}$ is the geomagnetic field vector and $\boldsymbol{T}_{i}$ is the total-field vector, both at $\left(x_{i}\right.$, $\left.y_{i}, z_{i}\right)$. The total-field vector can be represented by the sum

$\boldsymbol{T}_{i}=\boldsymbol{F}_{i}+\boldsymbol{B}_{i}$,

where $\boldsymbol{B}_{i}$ is the total magnetic induction vector produced by all magnetic sources (magnetized anomalous susceptibility distribution) at the position $\left(x_{i}, y_{i}, z_{i}\right)$ (Blakely, 1996; Langel and Hinze, 1998).

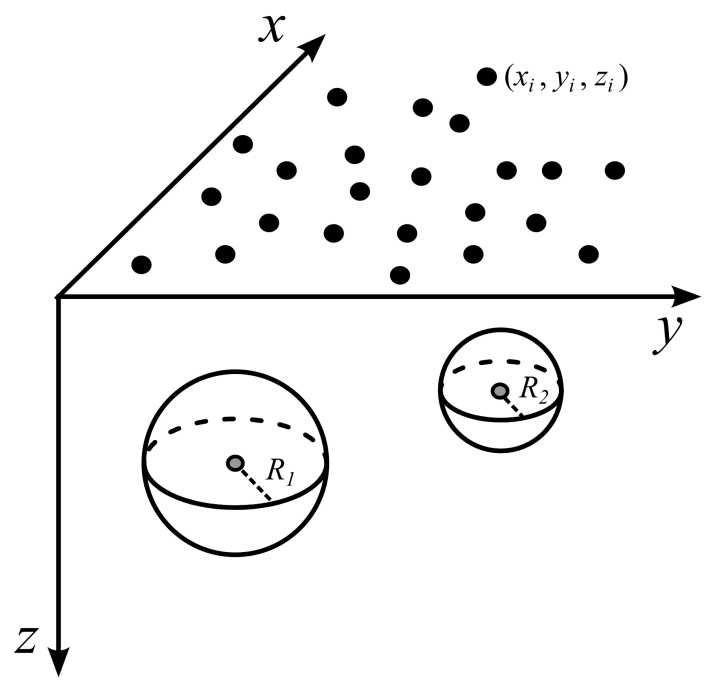

Figure 1. Schematic representation of $L=2$ spheres uniformly magnetized at the subsurface. These spheres have radii $R_{j}$ (dashed straight lines), constant magnetization vectors $\boldsymbol{m}^{j}$ and centres (grey dots) at $\left(x c_{j}, y c_{j}, z c_{j}\right), j=1, \ldots, L$. The magnetic effect produced by these spheres can be observed at the points $\left(x_{i}, y_{i}, z_{i}\right), i=$ $1, \ldots, N$ (black dots). In this Cartesian coordinate system, $x$ points to the geographic north, $y$ points east and $z$ points downward.

For local- or regional-scale magnetic studies, it is very common to consider that (i) the geomagnetic field $\boldsymbol{F}_{i}$ (Eq. 1) is a constant vector $\boldsymbol{F}_{0}$ throughout the study area and (ii) that $\left\|\boldsymbol{F}_{0}\right\| \gg\left\|\boldsymbol{B}_{i}\right\|, i=1, \ldots, N$ (Telford et al., 1990; Blakely, 1996). The second assumption is equivalent to saying that the total magnetic induction $\boldsymbol{B}_{i}$ (Eq. 1) is a small perturbation of the geomagnetic field $\boldsymbol{F}_{i}$ throughout the study area. These two assumptions make it possible to approximate the Euclidean norm of the total-field vector $\boldsymbol{T}_{i}$ (Eq. 1) by a first-order Taylor expansion as follows:

$$
\begin{aligned}
\left\|\boldsymbol{T}_{i}\right\| & \approx\left\|\boldsymbol{F}_{0}+\boldsymbol{B}_{i}\right\| \\
& \approx\left\|\boldsymbol{F}_{0}\right\|+\hat{\boldsymbol{F}}^{\mathrm{T}} \boldsymbol{B}_{i},
\end{aligned}
$$

where the superscript $\mathrm{T}$ indicates transposition and

$$
\hat{\boldsymbol{F}}=\frac{\boldsymbol{F}_{0}}{\left\|\boldsymbol{F}_{0}\right\|}
$$

is a unit vector (with the same direction of the geomagnetic field $\boldsymbol{F}_{i}$ ) representing the gradient of the function $\left\|\boldsymbol{T}_{i}\right\|$ with respect to the components of the vector $\boldsymbol{T}_{i}$ (Blakely, 1996). By introducing this first-order Taylor expansion into the total-field anomaly (Eq. 1), we obtain the well-known approximated total-field anomaly given by

$\Delta T_{i} \approx \hat{\boldsymbol{F}}^{\mathrm{T}} \boldsymbol{B}_{i}, \quad i=1, \ldots, N$.

Let us consider that the magnetic sources can be represented by a set of $L$ uniformly magnetized spheres. In this 
case, the total magnetic induction $\boldsymbol{B}_{i}$ is given by

$\boldsymbol{B}_{i}=\sum_{j=1}^{L} \boldsymbol{b}_{i}^{j}, \quad i=1, \ldots, N$,

$\boldsymbol{b}_{i}^{j}$ being the magnetic induction produced, at the position $\left(x_{i}, y_{i}, z_{i}\right)$, by the $j$ th sphere, $j=1, \ldots, L$, with radius $R_{j}$ (dashed straight lines in Fig. 1), centre at $\left(x c_{j}, y c_{j}, z c_{j}\right)$ (grey dots in Fig. 1) and magnetization vector $\boldsymbol{m}^{j}$ given by

$\boldsymbol{m}^{j}=\left[\begin{array}{l}m x_{j} \\ m y_{j} \\ m z_{j}\end{array}\right]_{3 \times 1}$.

The magnetic induction $\boldsymbol{b}_{i}^{j}$ (Eq. 6) can be written as

$\boldsymbol{b}_{i}^{j}=C_{m} \mathbf{M}_{i}^{j} \frac{4}{3} \pi R_{j}^{3} \boldsymbol{m}^{j}$,

where $C_{m}$ is a constant given by $\mu_{0} / 4 \pi=10^{-7} \mathrm{H} / \mathrm{m}, \mu_{0}$ is the vacuum permeability and $\mathbf{M}_{i}^{j}$ is the matrix

$\mathbf{M}_{i}^{j}=\left[\begin{array}{lll}\left(\frac{\partial^{2}}{\partial x \partial x} \frac{1}{r_{j}}\right) & \left(\frac{\partial^{2}}{\partial x \partial y} \frac{1}{r_{j}}\right) & \left(\frac{\partial^{2}}{\partial x \partial z} \frac{1}{r_{j}}\right) \\ \left(\frac{\partial^{2}}{\partial x \partial y} \frac{1}{r_{j}}\right) & \left(\frac{\partial^{2}}{\partial y \partial y} \frac{1}{r_{j}}\right) & \left(\frac{\partial^{2}}{\partial y \partial z} \frac{1}{r_{j}}\right) \\ \left(\frac{\partial^{2}}{\partial x \partial z} \frac{1}{r_{j}}\right) & \left(\frac{\partial^{2}}{\partial y \partial z} \frac{1}{r_{j}}\right) & \left(\frac{\partial^{2}}{\partial z \partial z} \frac{1}{r_{j}}\right)\end{array}\right]_{3 \times 3}$,

whose elements are the second derivatives, evaluated at the position $\left(x_{i}, y_{i}, z_{i}\right)$, of the function

$\frac{1}{r_{j}} \equiv \frac{1}{\sqrt{\left(x-x c_{j}\right)^{2}+\left(y-y c_{j}\right)^{2}+\left(z-z c_{j}\right)^{2}}}$

with respect to the variables $x, y$ and $z$. By substituting the magnetic induction $\boldsymbol{b}_{i}^{j}$ (Eq. 8) into the total magnetic induction vector $\boldsymbol{B}_{i}$ (Eq. 6) and using the approximated total-field anomaly (Eq. 5), we obtain the predicted total-field anomaly $d_{i}$ produced by the set of $L$ spheres at the position $\left(x_{i}, y_{i}, z_{i}\right)$ as follows:

$d_{i}=\hat{\boldsymbol{F}}^{\mathrm{T}} \sum_{j=1}^{L} \mathbf{M}_{i}^{j} \boldsymbol{h}^{j}$,

where

$\boldsymbol{h}^{j}=C_{m} \frac{4}{3} \pi R_{j}^{3} \boldsymbol{m}^{j}, \quad j=1, \ldots, L$.

This equation shows that each vector $\boldsymbol{h}^{j}$ has the same direction of the magnetization vector $\boldsymbol{m}^{j}, j=1, \ldots, L$ (Eq. 7). In Cartesian coordinates, we have $\boldsymbol{h}^{j}=\left[h x_{j} h y_{j} h z_{j}\right]^{\mathrm{T}}$ (Fig. 2), where $h \alpha_{j}=C_{m} \frac{4}{3} \pi R_{j}^{3} m \alpha_{j}, \alpha=x, y, z, j=1, \ldots, L$, and $m \alpha_{j}, \alpha=x, y, z$, are the elements of the magnetization vector $\boldsymbol{m}^{j}$ (Eq. 7). Equation (11) can be rewritten as

$d_{i}(\boldsymbol{h})=\boldsymbol{a}_{i}^{\mathrm{T}} \boldsymbol{h}$

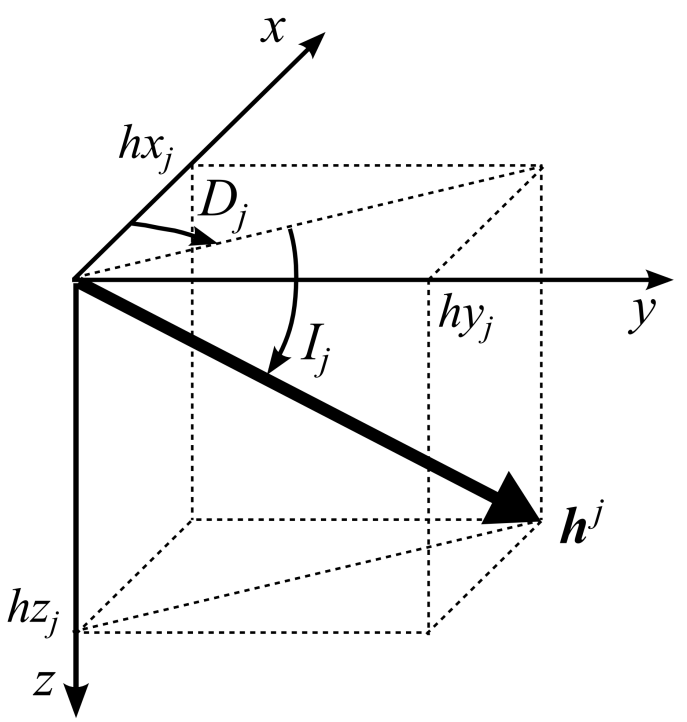

Figure 2. Schematic representation of the vector $\boldsymbol{h}^{j}$ (Eq. 12) with elements $h x_{j}, h y_{j}$ and $h z_{j}$ in Cartesian coordinates. This vector has a declination $D_{j}$ (positive in the clockwise sense) and inclination $I_{j}$ (positive downward), $j=1, \ldots, L$.

where

$\boldsymbol{h}=\left[\begin{array}{c}\boldsymbol{h}^{1} \\ \vdots \\ \boldsymbol{h}^{L}\end{array}\right]_{3 L \times 1}$,

and

$\boldsymbol{a}_{i}=\left[\begin{array}{c}\mathbf{M}_{i}^{1} \hat{\boldsymbol{F}} \\ \vdots \\ \mathbf{M}_{i}^{L} \hat{\boldsymbol{F}}\end{array}\right]_{3 L \times 1}$.

Note that, in Eq. (13), the predicted total-field anomaly $d_{i}$ (Eq. 11) is represented by $d_{i}(\boldsymbol{h})$ in order to express its dependence on the parameter vector $\boldsymbol{h}$ (Eq. 14). The linear relationship given by Eq. (13) can be written in matrix notation as

$\boldsymbol{d}(\boldsymbol{h})=\mathbf{A} \boldsymbol{h}$,

where $\boldsymbol{d}(\boldsymbol{h})$ is the $N$-dimensional predicted data vector, whose $i$ th element is $d_{i}$ (h) (Eq. 13), and $\mathbf{A}$ is an $N \times 3 L$ matrix $(N>3 L)$ that can be partitioned as

$\mathbf{A}=\left[\begin{array}{c}\boldsymbol{a}_{1}^{\mathrm{T}} \\ \vdots \\ \boldsymbol{a}_{N}^{\mathrm{T}}\end{array}\right]_{N \times 3 L}$,

$\boldsymbol{a}_{i}, i=1, \ldots, N$, being the $3 L$-dimensional vector defined in Eq. (15). 


\subsection{Inverse problem}

We assume that the magnetic sources giving rise to the observed data $\Delta T^{0}$ can be approximated by a set of $L$ uniformly magnetized spheres with known coordinates $\left(x c_{j}\right.$, $\left.y c_{j}, z c_{j}\right), j=1, \ldots, L$, of their centres. We also assume that the direction of the constant geomagnetic field $\boldsymbol{F}_{0}$ (Eq. 4) is known. Under these hypotheses, we formulate an overdetermined linear inverse problem of estimating the parameter vector $\boldsymbol{h}$ (Eq. 14) from $\boldsymbol{\Delta} \boldsymbol{T}^{\mathrm{o}}$. The problem of estimating a parameter vector $\boldsymbol{h}$ (Eq. 14) containing the magnetization vectors $\boldsymbol{m}^{j}$ (Eq. 7), $j=1, \ldots, L$, of the $L$ spheres can be done by minimizing the goal function

$\Psi(\boldsymbol{h})=\frac{1}{N}\left[\boldsymbol{\Delta} \boldsymbol{T}^{\mathrm{o}}-\boldsymbol{d}(\boldsymbol{h})\right]^{\mathrm{T}}\left[\boldsymbol{\Delta} \boldsymbol{T}^{\mathrm{o}}-\boldsymbol{d}(\boldsymbol{h})\right]$.

Differentiating Eq. (18) with respect to $\boldsymbol{h}$ and equating the result to the null vector, we obtain the normal equation for the least-squares estimate $\hat{\boldsymbol{h}}$, i.e.

$$
\left(\mathbf{A}^{\mathrm{T}} \mathbf{A}\right) \hat{\boldsymbol{h}}=\mathbf{A}^{\mathrm{T}} \boldsymbol{\Delta} \boldsymbol{T}^{\mathrm{o}} .
$$

The least-squares estimate $\hat{\boldsymbol{h}}$ (Eq. 19) minimizes the goal function (Eq. 18) and produces the predicted data $\boldsymbol{d}(\hat{\boldsymbol{h}})$ (Eq. 16) as near as possible to the observed data $\Delta T^{\mathrm{o}}$, in the L2-norm sense (Bard, 1973; Twomey, 1977; Menke, 1989; Aster et al., 2005).

The least-squares estimate $\hat{\boldsymbol{h}}$ (Eq. 19) is very sensitive to outliers in the observed data. In some cases, if the outliers are not properly removed from the observed data, the estimated parameters can be seriously misleading. When working with field data, the outliers can be caused by interfering magnetic sources or cultural noise, for example. To counteract this problem automatically, we can use a robust scheme for minimizing the goal function

$\Gamma(\boldsymbol{h})=\frac{1}{N} \sum_{i=1}^{N}\left|\Delta T_{i}^{\mathrm{o}}-d_{i}(\boldsymbol{h})\right|$.

Different from Eq. (18), the parameter vector $\boldsymbol{h}$ minimizing Eq. (20) cannot be obtained by solving a linear system. One practical way is the iteratively reweighted least squares algorithm (Scales et al., 1988; Farquharson and Oldenburg, 1998; Aster et al., 2005). In this algorithm, at each iteration $k$, the following linear system is solved:

$\left(\mathbf{A}^{\mathrm{T}} \mathbf{R}^{k} \mathbf{A}\right) \tilde{\boldsymbol{h}}^{k+1}=\mathbf{A}^{\mathrm{T}} \mathbf{R}^{k} \boldsymbol{\Delta} \boldsymbol{T}^{\mathrm{o}}$, where $\mathbf{R}^{k}$ is a diagonal $N \times N$ matrix whose $i$ th element $r_{i}^{k}$, $i=1, \ldots, N$, is given by

$r_{i}^{k}=\frac{1}{\left|\Delta T_{i}^{\mathrm{o}}-d_{i}\left(\widetilde{\boldsymbol{h}}^{k}\right)+\epsilon\right|}$,

$\epsilon$ being a small positive number used to prevent singularities. This iterative process begins (iteration $k=0$ ) with the leastsquares estimate $\widetilde{\boldsymbol{h}}^{0}=\hat{\boldsymbol{h}}$ (Eq. 19). With this initial approximation $\widetilde{\boldsymbol{h}}^{0}$, we calculate the matrix $\mathbf{R}^{0}$ (Eq. 22). By using the matrix $\mathbf{R}^{0}$, we solve the linear system given by Eq. (21) for obtaining the estimate $\widetilde{\boldsymbol{h}}^{1}$. By using the updated estimate $\widetilde{\boldsymbol{h}}^{1}$, we calculate the matrix $\mathbf{R}^{1}$ (Eq. 22), solve the linear system (Eq. 21) for obtaining the updated estimate $\widetilde{\boldsymbol{h}}^{2}$, and so on. After some iterations, this iterative procedure converges to the estimate $\widetilde{\boldsymbol{h}}$, which is named a robust estimate and is an approximation of the parameter vector minimizing the function $\Gamma(\boldsymbol{h})$ (Eq. 20).

Both $\hat{\boldsymbol{h}}$ (least-squares estimate) and $\tilde{\boldsymbol{h}}$ (robust estimate) are estimates of the Cartesian coordinates of the parameter vector $\boldsymbol{h}$ (Eq. 14), which is represented as a function of the vectors $\boldsymbol{h}^{j}, j=1, \ldots, L$ (Eq. 12) and the magnetization vectors $\boldsymbol{m}^{j}, j=1, \ldots, L$ (Eq. 7). However, magnetization vectors are commonly represented in terms of its intensity, declination and inclination. Therefore, for convenience, we will represent the vectors $\boldsymbol{h}^{j}$ (Eq. 12) in spherical coordinates as follows:

$\boldsymbol{h}^{j}=Q_{j}\left[\begin{array}{c}\cos I_{j} \cos D_{j} \\ \cos I_{j} \sin D_{j} \\ \sin I_{j}\end{array}\right]_{3 \times 1}$,

where the intensity $Q_{j}$, declination $D_{j}$ and inclination $I_{j}$ are given as functions of the elements $h x_{j}, h y_{j}$ and $h z_{j}$ (Fig. 2) of $\boldsymbol{h}^{j}$, i.e.

$Q_{j}=\sqrt{h x_{j}^{2}+h y_{j}^{2}+h z_{j}^{2}}$,

$D_{j}=\arctan \left(\frac{h y_{j}}{h x_{j}}\right)$,

and

$I_{j}=\arctan \left(\frac{h z_{j}}{\sqrt{h x_{j}^{2}+h y_{j}^{2}}}\right)$.

Note that, according to Eq. (12), the declinations $D_{j}$ (Eq. 25) and inclinations $I_{j}$ (Eq. 26), $j=1, \ldots, L$, are equal to those ones of the magnetization vectors $\boldsymbol{m}^{j}, j=1, \ldots, L$ (Eq. 7). After obtaining the least-squares estimate $\hat{\boldsymbol{h}}$ or the robust estimate $\widetilde{\boldsymbol{h}}$ in Cartesian coordinates, we calculate the declinations $\hat{D}_{j}$ or $\widetilde{D}_{j}$ (Eq. 25) and inclinations $\hat{I}_{j}$ or $\widetilde{I}_{j}$ (Eq. 26), $j=1, \ldots, L$, of the total magnetization vector of all spheres. We use a caret $\left(^{\wedge}\right)$ and a tilde $(\sim)$ to distinguish estimates of the declinations and inclinations which are computed by using, respectively, the least-square estimate $\hat{\boldsymbol{h}}$ and the robust estimate $\widetilde{\boldsymbol{h}}$. 


\subsection{Uncertainty of the estimated parameters}

In a magnetic survey, the measurements are always affected by noise due to the wide range of experimental errors and inaccuracies that happen in a geophysical survey. The noise in the observed data $\Delta T^{\mathrm{o}}$ affects the estimated parameter vector, independently of the used method. To quantify this effect on the estimated parameters, we can use the propagation of covariance (Bard, 1973; Aster et al., 2005). By presuming that the errors of all observed data $\Delta T_{i}^{\mathrm{o}}, i=1, \ldots, N$, are independent and of equal variance $\sigma^{2}$, we obtain the data covariance matrix $\mathbf{D}=\sigma^{2} \mathbf{I}$, where $\mathbf{I}$ is the $N \times N$ identity matrix. The parameter covariance matrix $\hat{\mathbf{C}}$ of the least-squares estimate $\hat{\boldsymbol{h}}$ (Eq. 19) is given by

$\hat{\mathbf{C}}=\hat{\mathbf{H D}} \hat{\mathbf{H}}^{\mathrm{T}}$,

where

$\hat{\mathbf{H}}=\left(\mathbf{A}^{\mathrm{T}} \mathbf{A}\right)^{-1} \mathbf{A}^{\mathrm{T}}$.

Similarly, the parameter covariance matrix $\widetilde{\mathbf{C}}$ of the robust estimate $\widetilde{\boldsymbol{h}}$ (Eqs. 21 and 22) can be given by

$\widetilde{\mathbf{C}}=\widetilde{\mathbf{H}} \mathbf{D} \widetilde{\mathbf{H}}^{\mathrm{T}}$,

where

$\widetilde{\mathbf{H}}=\left(\mathbf{A}^{\mathrm{T}} \mathbf{R}^{k} \mathbf{A}\right)^{-1} \mathbf{A}^{\mathrm{T}} \mathbf{R}^{k}$,

and the matrix $\mathbf{R}^{k}$ (Eq. 21) is the last one calculated in the iterative process for estimating $\widetilde{\boldsymbol{h}}$ (Bard, 1973; Aster et al., 2005).

The diagonal of the parameter covariance matrices $\hat{\mathbf{C}}$ (Eq. 27) and $\widetilde{\mathbf{C}}$ (Eq. 29) contains the variances of the elements of the estimates $\hat{\boldsymbol{h}}$ (Eq. 19) and $\widetilde{\boldsymbol{h}}$ (Eqs. 21 and 22), respectively. Let $\boldsymbol{v}$ be a $3 L$-dimensional vector whose element $v_{j}, j=1, \ldots, 3 L$, represents the $j$ th element of the diagonal of the covariance matrix $\hat{\mathbf{C}}$ (Eq. 27) or $\widetilde{\mathbf{C}}$ (Eq. 29). This vector can be represented by

$\boldsymbol{v}=\left[\begin{array}{c}\boldsymbol{v}^{1} \\ \vdots \\ \boldsymbol{v}^{L}\end{array}\right]_{3 L \times 1}$,

where

$\boldsymbol{v}^{j}=\left[\begin{array}{c}\left(\sigma x_{j}\right)^{2} \\ \left(\sigma y_{j}\right)^{2} \\ \left(\sigma z_{j}\right)^{2}\end{array}\right]_{3 \times 1}$,

and $\sigma \alpha_{j}, \alpha=x, y, z, j=1, \ldots, L$, are the uncertainties of the components $h \alpha_{j}, \alpha=x, y, z, j=1, \ldots, L$, of the vectors $\boldsymbol{h}^{j}, j=1, \ldots, L$ (Eq. 12), forming the estimated parameter vector $\hat{\boldsymbol{h}}$ or $\tilde{\boldsymbol{h}}$. The uncertainties of the intensity $Q_{j}$, declination $D_{j}$ and inclination $I_{j}$ can be given as functions of the uncertainties $\sigma \alpha_{j}, \alpha=x, y, z, j=1, \ldots, L$ (Eq. 32). To do it, we use the propagation of uncertainties (Fornasini, 2008) and presume that the components $h \alpha_{j}, \alpha=x, y, z, j=1, \ldots, L$, of the vector $\boldsymbol{h}^{j}$ (Eq. 12) are statistically independent. From this assumption, the uncertainties $\sigma_{Q j}, \sigma_{D j}$ and $\sigma_{I j}$ of the intensity $Q_{j}$ (Eq. 24), declination $D_{j}$ (Eq. 25) and inclination $I_{j}$ (Eq. 26) are respectively given by

$\sigma_{Q j}=\sqrt{\left(\frac{\partial Q_{j}}{\partial h x_{j}} \sigma x_{j}\right)^{2}+\left(\frac{\partial Q_{j}}{\partial h y_{j}} \sigma y_{j}\right)^{2}+\left(\frac{\partial Q_{j}}{\partial h z_{j}} \sigma z_{j}\right)^{2}}$,

$\sigma_{D j}=\sqrt{\left(\frac{\partial D_{j}}{\partial h x_{j}} \sigma x_{j}\right)^{2}+\left(\frac{\partial D_{j}}{\partial h y_{j}} \sigma y_{j}\right)^{2}}$

and

$\sigma_{I j}=\sqrt{\left(\frac{\partial I_{j}}{\partial h x_{j}} \sigma x_{j}\right)^{2}+\left(\frac{\partial I_{j}}{\partial h y_{j}} \sigma y_{j}\right)^{2}+\left(\frac{\partial I_{j}}{\partial h z_{j}} \sigma z_{j}\right)^{2}}$.

The first-order derivatives shown in Eqs. (33), (34) and (35) are given by

$$
\begin{aligned}
\frac{\partial Q_{j}}{\partial h \alpha_{j}} & =\frac{h \alpha_{j}}{Q_{j}}, \alpha=x, y, z, \\
\frac{\partial D_{j}}{\partial h x_{j}} & =\frac{-h y_{j}}{\left(h x_{j}\right)^{2}+\left(h y_{j}\right)^{2}}, \\
\frac{\partial D_{j}}{\partial h y_{j}} & =\frac{h x_{j}}{\left(h x_{j}\right)^{2}+\left(h y_{j}\right)^{2}}, \\
\frac{\partial I_{j}}{\partial h \alpha_{j}} & =\frac{-h \alpha_{j} h z_{j}}{Q_{j}^{2} \sqrt{\left(h x_{j}\right)^{2}+\left(h y_{j}\right)^{2}}}, \alpha=x, y,
\end{aligned}
$$

and

$\frac{\partial I_{j}}{\partial h z_{j}}=\frac{\sqrt{\left(h x_{j}\right)^{2}+\left(h y_{j}\right)^{2}}}{Q_{j}^{2}}$.

We use a caret $\left({ }^{\wedge}\right)$ and a tilde $\left({ }^{\sim}\right)$ to distinguish the uncertainties $(\hat{\sigma}$ and $\tilde{\sigma})$ computed by using, respectively, the leastsquares $\hat{\boldsymbol{h}}$ and the robust $\tilde{\boldsymbol{h}}$ estimates.

\subsection{Software implementation}

The inversion method described above is implemented in version 0.3 of the open-source Python language library Fatiando a Terra ${ }^{12}$. We used matplot 1 ib (Hunter, 2007) for graphs and maps and Mayavi (Ramachandran and Varoquaux, 2011) for 3-D figures. The results and figures from the application to synthetic and real data were produced in IPython notebooks (Pérez and Granger, 2007). The notebooks contain explanatory text as well as the source code

\footnotetext{
${ }^{1}$ http://www.fatiando.org/

${ }^{2}$ http://dx.doi.org/10.5281/zenodo. 16205
} 
Table 1. Test with the synthetic data (Fig. 3a) produced by a sphere and a rectangular prism. Comparison between the estimated and true values of the magnetization declination $D$ and inclination $I$. The uncertainties $\sigma_{\mathrm{D}}$ and $\sigma_{\mathrm{I}}$ (shown between parentheses) are calculated by using Eqs. (34) and (35). All values are in degrees $\left(^{\circ}\right)$. We use a caret $\left({ }^{\wedge}\right)$ and a tilde $(\sim)$ to distinguish the quantities computed by using, respectively, the least-squares $\hat{\boldsymbol{h}}$ and robust $\tilde{\boldsymbol{h}}$ estimates.

\begin{tabular}{llcrc}
\hline \multicolumn{2}{l}{ Sphere } & & Prism & \\
\hline$D$ & -10.00000 & - & -40.00000 & - \\
$\hat{D}$ & -10.07141 & $(0.00001)$ & -40.63733 & $(0.00113)$ \\
$\widetilde{D}$ & -10.03229 & $(0.00130)$ & -40.24585 & $(0.03601)$ \\
\hline$I$ & -20.00000 & - & 30.00000 & - \\
$\hat{I}$ & -19.99437 & $(0.00001)$ & 31.04075 & $(0.00068)$ \\
$\widetilde{I}$ & -20.01263 & $(0.00042)$ & 30.60551 & $(0.02047)$ \\
\hline
\end{tabular}

used to generate the synthetic data, run the inversions, and produce figures. The IPython notebooks and instructions for installing the required software and reproducing our results are available as online supplementary material ${ }^{34}$.

\section{Application to synthetic data}

\subsection{Validation test}

Figure 3a shows the synthetic noise-corrupted total-field anomaly produced by two uniformly magnetized bodies embedded in non-magnetic host rocks. The first one is a sphere with radius $1000 \mathrm{~m}$, centre at $x c=3000 \mathrm{~m}, y c=$ $3000 \mathrm{~m}, z c=1000 \mathrm{~m}$ and magnetization vector with intensity $6 \mathrm{~A} \mathrm{~m}^{-1}$, declination $10^{\circ}$ and inclination $20^{\circ}$. The second synthetic body is a rectangular prism with horizontal and vertical dimensions equal to $1000 \mathrm{~m}$, depth of the top at $200 \mathrm{~m}$, centre at $x c=7000 \mathrm{~m}, y c=7000 \mathrm{~m}, z c=700 \mathrm{~m}$ and $\mathrm{mag}$ netization vector with intensity $6 \mathrm{~A} \mathrm{~m}^{-1}$, declination $40^{\circ}$ and inclination $30^{\circ}$. We simulated a constant geomagnetic field $\boldsymbol{F}^{\mathrm{o}}$ (Eq. 3) with declination $15^{\circ}$ and inclination $10^{\circ}$. The total field anomaly produced by these synthetic bodies (indicated by A and B in Fig. 3) was calculated at $N=10000$ irregularly spaced points $\left(x_{i}, y_{i}, z_{i}\right), i=1, \ldots, N$, on the plane with constant vertical coordinate $z=-150 \mathrm{~m}$, extending from 0 to $10000 \mathrm{~m}$ in both the $x$ and $y$ directions. The pseudo-random Gaussian noise added has a zero mean and a standard deviation of $5 \mathrm{nT}$.

By assigning the correct positions of the centres of the simulated bodies, we invert the noise-corrupted total-field anomaly (Fig. 3a) to obtain the least-squares estimate $\hat{\boldsymbol{h}}$ (Eq. 19) and robust estimate $\widetilde{\boldsymbol{h}}$ (Eqs. 21 and 22). Next, we use these estimates to calculate the estimated declinations and inclinations (Eqs. 25 and 26). Finally, we calculate the
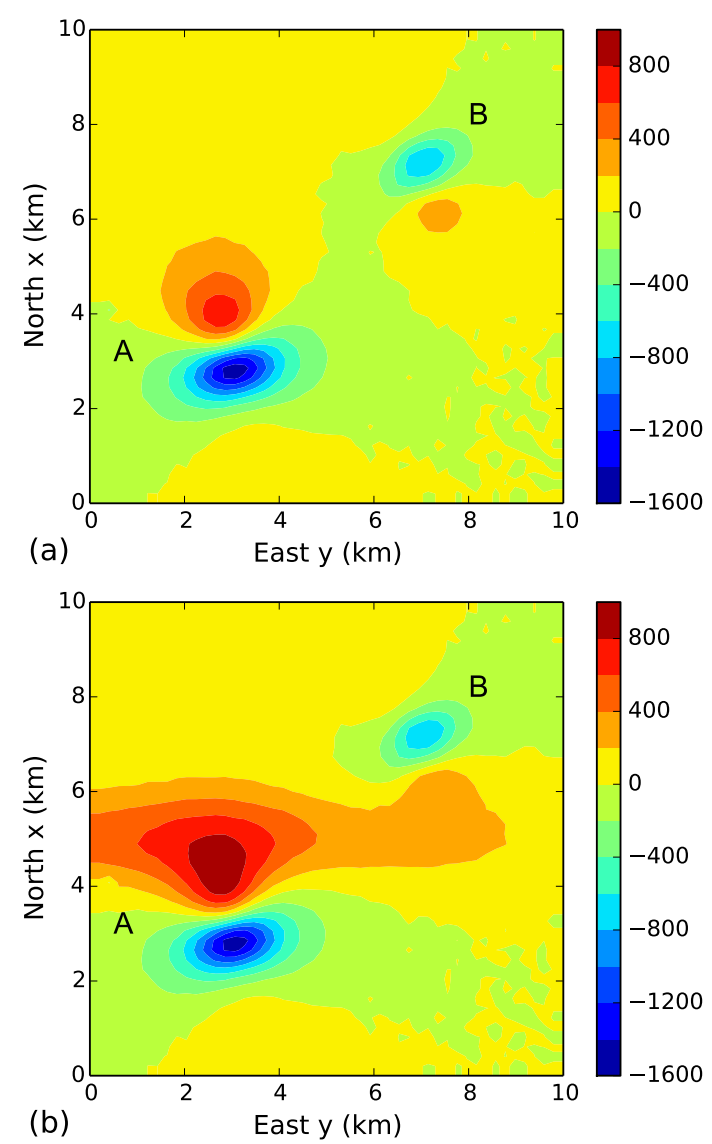

Figure 3. Validation test and robustness against interfering anomalies. (a) Synthetic noise-corrupted total field anomaly produced (nT) by a sphere and a rectangular prism. (b) Synthetic anomaly shown in (a) plus produced by an interfering anomaly. The anomalies produced by the sphere and prism are pinpointed as (A) and (B), respectively.

uncertainties using the propagation of covariance (Eqs. 2730 ) and assume that the standard deviation of the errors is equal to the true one $(\sigma=5 \mathrm{nT})$. The results (Table 1$)$ show that our method is able to retrieve the magnetization directions of the true sources by using either the least-squares or robust estimate. Even in the case of the prism that violates the premise assumed by our method that the bodies can be approximated by spheres, the estimates are very close to the true ones with small uncertainties. We can attribute this good performance of our method to three factors: (i) the absence of interfering signals produced, for example, by multiple magnetic sources; (ii) the simulated prism is a cube that seems a sphere-like body; and (iii) the use of the correct locations of the centres of the simulated bodies. The following tests will show how these factors affect the results obtained by using the least-squares and robust estimates.

\footnotetext{
${ }^{3}$ https://github.com/pinga-lab/

${ }^{4}$ http://dx.doi.org/10.5281/zenodo.16191
} 


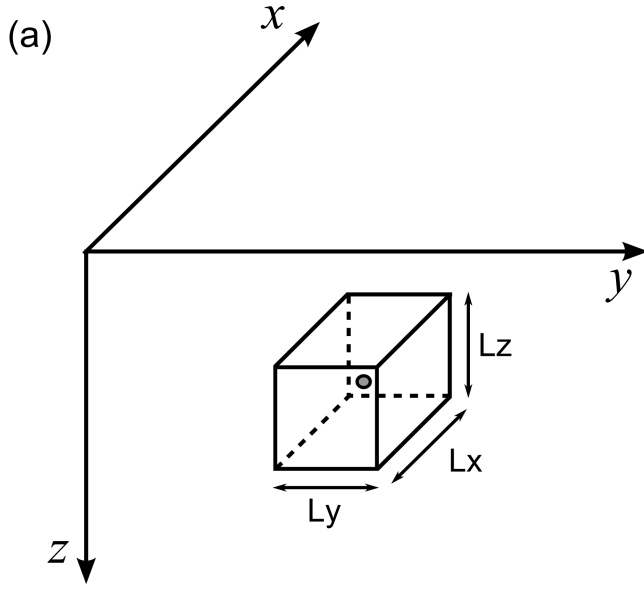

(b)

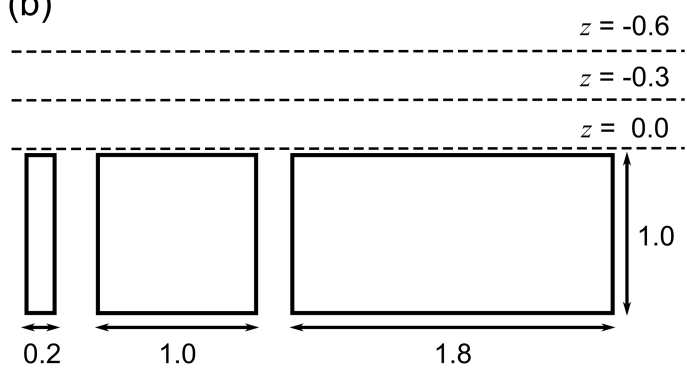

Figure 4. Robustness against non-spherical sources. (a) Rectangular prism with dimensions $L x, L y$ and $L z$ and centre at the grey dot. (b) Projection of three prisms on the plane $y z$. All prisms have top at $z=10 \mathrm{~m}$ and side lengths $L x=L z=1000 \mathrm{~m}$. The horizontal dimension $L y$ of each prism is equal to 200, 1000 and $1800 \mathrm{~m}$. The dashed lines represent the vertical coordinate $z$ of three different horizontal planes above the prisms. For convenience, all coordinates and lengths are normalized by the numerical value of $L z$ $(1000 \mathrm{~m})$ to obtain dimensionless quantities.

\subsection{Robustness against interfering anomalies}

Figure $3 \mathrm{~b}$ shows the noise-corrupted total-field anomaly shown in Fig. 3a contaminated with interfering anomalies. These interfering anomalies are characterized by midwavelength components which mostly affect the positive signals of the original total-field anomaly (Fig. 3a), resulting in non-dipolar total-field anomalies (Fig. 3b). The interfering anomalies reach approximately $33 \%$ of the positive amplitude of the original total-field anomaly shown in Fig. 3a. Notice that this test violates the premise assumed by our method that the total-field anomalies are caused by dipolar bodies (spheres). Although these interfering anomalies are different from random Gaussian noise or outliers marked as spurious errors dominated by short-wavelength spectral contents, they can also be seen as a data noise.

We repeated the numerical test presented in the previous section (Sect. 3.1), but using the contaminated total-field anomaly shown in Fig. $3 b$. The results are shown in Table 2.
Table 2. Test with the synthetic data (Fig. 3b) produced by a sphere and a rectangular prism. Comparison between the estimated and true values of the magnetization declination $D$ and inclination $I$. The uncertainties $\sigma_{\mathrm{D}}$ and $\sigma_{\mathrm{I}}$ (shown between parentheses) are calculated by using Eqs. (34) and (35). All values are in degrees $\left(^{\circ}\right)$. We use a caret $\left({ }^{\wedge}\right)$ and a tilde $(\sim)$ to distinguish the quantities computed by using, respectively, the least-squares $\hat{\boldsymbol{h}}$ and robust $\widetilde{\boldsymbol{h}}$ estimates.

\begin{tabular}{llcrc}
\hline \multicolumn{3}{c}{ Sphere } & & Prism \\
\hline$D$ & -10.00000 & - & -40.00000 & - \\
$\hat{D}$ & -4.28547 & $(0.00001)$ & -23.63607 & $(0.00130)$ \\
$\widetilde{D}$ & -8.73648 & $(0.00135)$ & -39.37397 & $(0.03679)$ \\
\hline$I$ & -20.00000 & - & 30.00000 & - \\
$\hat{I}$ & -25.11757 & $(0.00001)$ & 39.08012 & $(0.00064)$ \\
$\widetilde{I}$ & -21.75674 & $(0.00027)$ & 33.40926 & $(0.01648)$ \\
\hline
\end{tabular}

As we can see, the results obtained with the least-squares estimate are very affected by the interfering anomalies if compared with those ones obtained by using the robust estimate. By comparing the true values of inclination $I$ and declination $D$ with those ones obtained with the least-squares estimate, the differences reach approximately $14^{\circ}$ in declination and $9^{\circ}$ in inclination. On the other hand, the differences between the results obtained with the robust estimate and the true values reach only $2^{\circ}$ in declination and $3^{\circ}$ in inclination. These results suggest that the least-squares estimate is more sensitive to interfering anomalies than the robust estimate.

\subsection{Robustness against non-spherical sources}

In the previous subsections, we applied our method to estimate the magnetization direction of a rectangular prism whose total-field anomaly is indicated by B in Fig. 3. This total-field anomaly is similar to one that would be produced by a sphere. Two factors contribute to this: (i) the prism has all edges equal to $1000 \mathrm{~m}$ and (ii) the distance between its top depth and the plane surface on which the data were calculated is $350 \mathrm{~m}$. In this subsection, we analyse the effect of these two factors on the results obtained with our method. To do it, we applied our method to estimate the magnetization direction of 11 rectangular prisms with different side lengths $L x, L y$ and $L z$ (Fig. 4a) and a top at $10 \mathrm{~m}$ deep. All prisms have uniform magnetization with intensity, declination and inclination equal to $6 \mathrm{~A} \mathrm{~m}^{-1},-40$ and $30^{\circ}$, respectively, centres at $x c=0 \mathrm{~m}, y c=0 \mathrm{~m}$ and $z c=510 \mathrm{~m}$, and side lengths $L x=L z=1000 \mathrm{~m}$. For simplicity, we adopted dimensionless quantities by normalizing all coordinates and lengths by the numerical value of $L z(1000 \mathrm{~m})$, implying that $L x=L z=1.0$. The only difference between these 11 prisms is the side length $L y$, which varies regularly from 0.2 to 1.8 . Figure $4 \mathrm{~b}$ shows the $x-y$ cross section of three different rectangular prisms with $L y$ equal to $0.2,1.0$ and 1.8. We calculated the noise-corrupted total-field anomalies produced by 

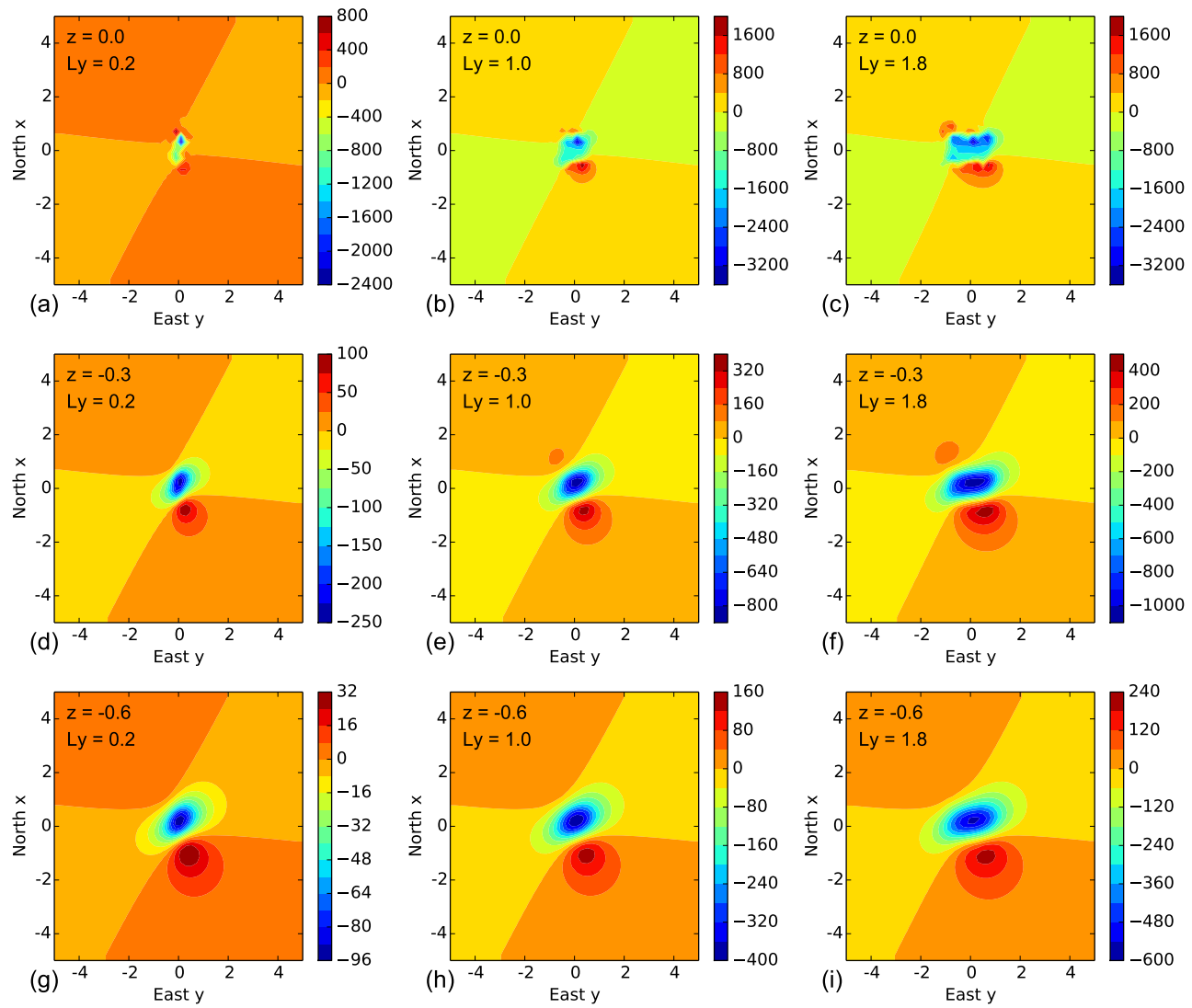

Figure 5. Robustness against non-spherical sources. Noise-corrupted total-field anomaly produced by each one of the three rectangular prisms shown in Fig. 4b on three horizontal planes with different constant vertical coordinates $z$ (dashed lines in Fig. 4b). We consider that the centres of all prisms are located at $x c=0.00, y c=0.00$ and $z c=0.51$. The intensity, declination and inclination of the magnetization vectors of all prisms are equal to $6 \mathrm{~A} \mathrm{~m}^{-1}$, and -40 and $30^{\circ}$, respectively. The simulated geomagnetic field is constant, with declination $-15^{\circ}$ and inclination $-10^{\circ}$. The data are in $\mathrm{nT}$ and all coordinates and lengths are dimensionless (see Fig. 4).

all prisms on horizontal planes with constant $z$ equal to 0.0 , -0.3 and -0.6 (dashed lines in Fig. 4b), resulting in 33 synthetic data sets. All data are calculated at $N=3000$ points irregularly spaced over an area extending from -5 to 5 along the $x$ and $y$ directions. The pseudo-random Gaussian noise added has a zero mean and a standard deviation of $5 \mathrm{nT}$. The simulated constant geomagnetic field $\boldsymbol{F}_{0}$ (Eq. 3) has declination $-15^{\circ}$ and inclination $-10^{\circ}$.

Figure 5a-c show that total-field anomalies calculated near to the sources are very different to those ones produced by spherical bodies (dipolar sources) and exhibit strongly nondipolar features. These non-dipolar features are attenuated if the data are calculated far from the sources (Fig. 5g-i), showing the well-known property that the magnetic field produced by a non-dipolar source tends to the field produced by a dipolar source at great distances. This attenuation is more noticeable for sources presenting symmetry around three orthogonal axes. This higher attenuation for symmetrical sources can be seen by comparing Fig. 5b, e and h, which show anomalies produced by a cube with $L x=L y=L z=1.0$, with Fig. 5a, $\mathrm{c}, \mathrm{d}, \mathrm{f}, \mathrm{g}$ and $\mathrm{i}$, which show anomalies produced by other rectangular prisms. For example, on the plane $z=-0.3$, the total-field anomaly produced by the cube (Fig. $5 \mathrm{~h}$ ) displays approximately a dipolar feature, while the total-field anomalies produced by the other prisms (Fig. $5 \mathrm{~d}$ and f) exhibit nondipolar features.

We applied our method to interpret these 33 data sets and the results are shown in Fig. 6. In all these applications, we presume the correct location of the centre of the sources. Figure 6 shows that the robust estimates (red dots) are much better than the least-squares estimates (blue dots). This better performance is noteworthy for the estimated declinations obtained by inverting the total-field anomalies near to the sources (red dots in Fig. 6a). The least-squares estimates (blue dots in Fig. 6a and b) seem to be more sensitive to the strong non-dipolar total-field anomalies (e.g. Fig. 5a-c). By inverting the total-field anomalies for the sources (e.g. Fig. $5 d-i)$, the least-squares estimates are approximately similar to the robust estimates (Fig. 6c-f).

The greater the distance between the sources and the data, the greater the attenuation of the non-dipolar features, and thus the smaller the difference between the least-squares and 

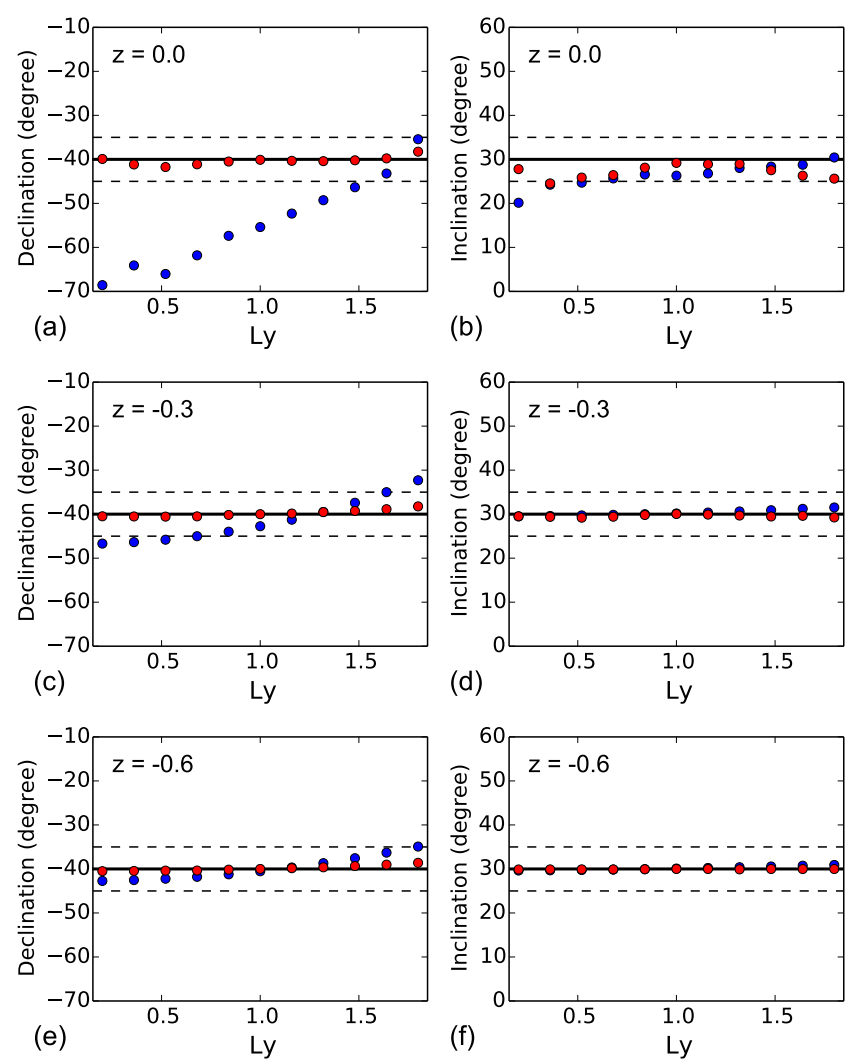

Figure 6. Robustness against non-spherical sources. The blue and red dots represent, respectively, the results obtained with the leastsquares $\hat{\boldsymbol{h}}$ (Eq. 19) and robust $\widetilde{\boldsymbol{h}}$ (Eqs. 21 and 22) estimates. Each dot represents an estimated declination or inclination obtained from the total-field anomaly produced by a rectangular prism with a different $L y$ (Fig. 4). $z$ indicates the constant vertical coordinate of the planar surface on which the total-field anomaly was calculated (dashed lines in Fig. 4b). The continuous black lines represent the true declinations (or inclinations). The dashed lines represent the true declination (or inclination) $\pm 5^{\circ}$.

robust estimates. In this case, a good practice when applying our method is to perform an upward continuation of the totalfield anomaly to be inverted.

\subsection{Robustness against errors in the centre location}

In all previous tests with synthetic data, we presume the correct location of the centre of the sources. However, in real world scenarios, the positions of the sources cannot be obtained directly and have to be estimated. This estimation can be done, for example, by using the Euler deconvolution technique (Thompson, 1982; Reid et al., 1990). This is a classical technique to estimate the 3-D position of magnetic sources (Reid et al., 2014; Uieda et al., 2014). Like all numerical techniques, the estimates obtained via Euler deconvolution contain errors that will affect the results obtained with our method. So, in this subsection, we analyse how the errors in the coordinates of the centre of the source affect the results obtained with our method.

We simulated a uniformly magnetized sphere (not shown) with centre at $x c=5000 \mathrm{~m}, y c=5000 \mathrm{~m}$ and $z c=1000 \mathrm{~m}$, radius $R=1000 \mathrm{~m}$ and magnetization vector with intensity $8.0 \mathrm{~A} \mathrm{~m}^{-1}$, declination $-13^{\circ}$ and inclination $-40^{\circ}$. The simulated constant geomagnetic field $\boldsymbol{F}_{0}$ (Eq. 3) has declination $-13^{\circ}$ and inclination $-9.5^{\circ}$. The noise-corrupted total-field anomaly (not shown) produced by this sphere is calculated at $N=2601$ points equally spaced on a plane with constant $z=-150 \mathrm{~m}$, extending from 0 to $10000 \mathrm{~m}$ along both the $x$ and $y$ axes. The pseudo-random Gaussian noise added has null mean and standard deviation equal to $2 \mathrm{nT}$.

We applied our method to these synthetic data for estimating the magnetization direction of the simulated spherical body. This application was done by presuming different locations of the centre of the source along three orthogonal straight lines which are parallel to the $x, y$ and $z$ axes and cross the centre of the simulated spherical body. Along each line, we varied the centre of the source at 21 points regularly spaced in a range of $2000 \mathrm{~m}$. The results obtained along the $x, y$ and $z$ axes are shown in Fig. 7a-f, respectively.

We can clearly see that the wrong choice of the $x$ and $y$ coordinates of the centre of the source leads to poor estimates of the magnetization direction (declinations and inclinations in Fig. 7a-d) when compared with the true magnetization vector (continuous black lines in Fig. 7). On the other hand, the estimated declinations and inclinations are less sensitive to the wrong choice of the $z$ coordinate of the centre of the source (Fig. 7e and f), especially the ones obtained by the least-squares estimate. These results show that our method is more sensitive to uncertainties in the prior information about the location of the centre of the source along the horizontal directions than in the vertical direction. Fortunately, the sensitivity of Euler deconvolution to estimating the 3-D position of magnetic sources works in the opposite direction. As shown by Silva and Barbosa (2003) and Melo et al. (2013), the estimates of the source horizontal positions in Euler deconvolution are very accurate, while the depth estimates may fail. This characteristic makes Euler deconvolution a suitable technique for providing the centre of the source to be used by our method as prior information to form the matrix given in Eq. (17).

\subsection{Complex tests}

In this section, we present the performance of our method in recovering the magnetization direction of synthetic sources simulating complex geological scenarios.

\subsubsection{Strongly interfering anomalies}

Figure 8 shows two synthetic sources simulating uniformly magnetized bodies embedded in non-magnetic host rocks. Both sources are rectangular prisms with horizontal dimen- 

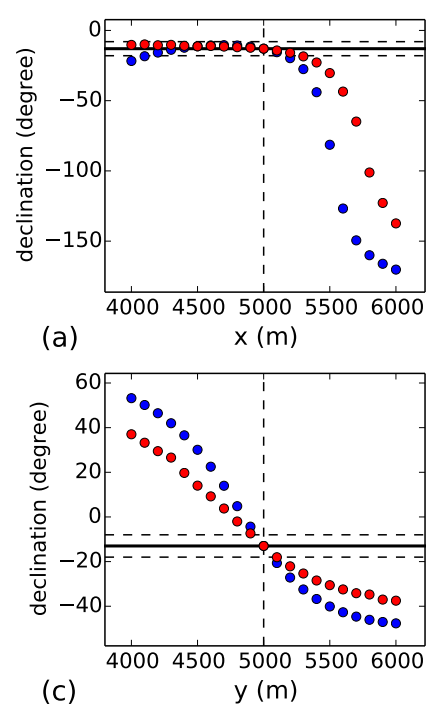

(c) $y(m)$

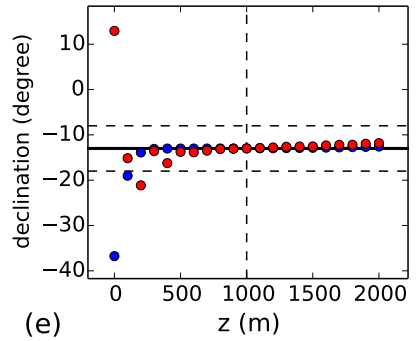

(e)

Figure 7. Robustness against errors in the centre location. The blue and red dots represent, respectively, the magnetization direction of a simulated spherical body obtained with the least-squares $\hat{\boldsymbol{h}}$ (Eq. 19) and robust $\widetilde{\boldsymbol{h}}$ (Eqs. 21 and 22) estimates. The estimated declinations and inclinations were obtained by presuming different positions for the centre of the source along the $x, y$ and $z$ axes. Along each axis, the magnetization direction was estimated by considering 21 different centres regularly spaced in a range of $2000 \mathrm{~m}$ on a line passing through the right coordinates of the centre of the simulated spherical body (vertical dashed lines). The continuous black lines represent the true declinations (or inclinations). The dashed lines represent the true declination (or inclination) $\pm 5^{\circ}$.

sions equal to 80 and $20 \mathrm{~m}$ along the $x$ and $y$ directions, respectively, vertical dimension equal to $70 \mathrm{~m}$ and depth of the top at $z=10 \mathrm{~m}$ (red prisms in Fig. 8). One source has its centre at $x c=0 \mathrm{~m}, y c=-30 \mathrm{~m}$ and $z c=45 \mathrm{~m}$, while the other one has its centre shifted $60 \mathrm{~m}$ in the positive $y$ direction (pinpointed black dots in Fig. 8). Both sources have a Koenigsberger ratio equal to 3 and the same induced magnetization with intensity $3 \mathrm{~A} \mathrm{~m}^{-1}$, declination $0^{\circ}$ and inclination $-30^{\circ}$. The remanent magnetization of the sources has the same inclination equal to $0^{\circ}$, but different declinations equal to $30^{\circ}$ (eastern source) and $-30^{\circ}$ (western source). The total field anomaly produced by these synthetic bodies (Fig. 9) was calculated at $N=2601$ regularly spaced points $\left(x_{i}, y_{i}, z_{i}\right)$, $i=1, \ldots, N$, on the plane with constant vertical coordinate $z=-10 \mathrm{~m}$, extending from -200 to $200 \mathrm{~m}$ in both the $x$ and $y$ directions. The pseudo-random Gaussian noise added has a

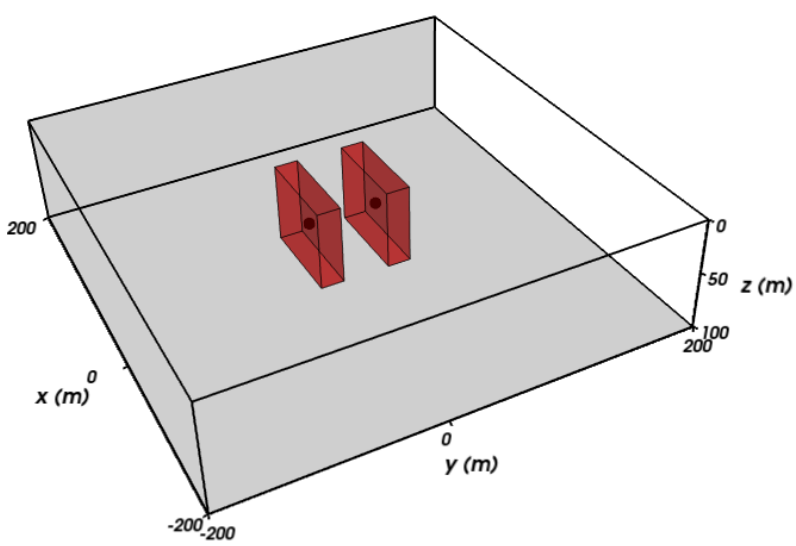

Figure 8. Strongly interfering anomalies. Synthetic prisms (in red) with side lengths equal to 80,20 , and $70 \mathrm{~m}$ along the $x, y$ and $z$ directions, respectively. Both prisms have a depth of the top at $z=$ $10 \mathrm{~m}$. The eastern prism has its centre at $x c=0 \mathrm{~m}, y c=-30 \mathrm{~m}$ and $z c=45 \mathrm{~m}$, while the western prism has its centre shifted $60 \mathrm{~m}$ in the positive $y$ direction (pinpointed black dots).

zero mean and a standard deviation equal to $2 \%$ of the peakto-peak amplitude of the noise-free total-field anomaly. This synthetic test was inspired by a test shown in Lelièvre and Oldenburg (2009).

By assigning the correct positions of the centres of the simulated bodies, we invert the noise-corrupted total-field anomaly (Fig. 9) to obtain the least-squares estimate $\hat{\boldsymbol{h}}$ (Eq. 19) and robust estimate $\widetilde{\boldsymbol{h}}$ (Eqs. 21 and 22). Next, we use these estimates to calculate the estimated declinations and inclinations (Eqs. 25 and 26). Finally, we calculate the uncertainties using the propagation of covariance (Eqs. 2730 ) by assuming that the standard deviation of the errors is equal to the true one. The results (Table 3) show the good performance of our method in estimating the magnetization directions of non-spherical sources producing strongly interfering anomalies. This test also shows the better performance of the robust estimate as compared with the least-squares estimate.

\subsubsection{Igneous intrusion within a sedimentary basin}

Figure 10 shows a 2-D schematic representation of a synthetic geological setting where an igneous intrusion (red prisms) is embedded in a non-magnetic sedimentary pack (grey area). The igneous intrusion is made up of a sill which is fed by a vertical pipe, and its top is $200 \mathrm{~m}$ deep. The sediments overlay a basement (white area) which is magnetized by induction (with intensity $0.1 \mathrm{~A} \mathrm{~m}^{-1}$ ) and generates a regional anomaly (not shown). The sedimentary package and basement are semi-infinite along the $x$ axis. The simulated geomagnetic field has inclination $-39.8^{\circ}$ and declination $-22.5^{\circ}$. The synthetic intrusion has a reversed magnetization with inclination $I=39.8^{\circ}$, declination $D=157.5^{\circ}$ and intensity $6 \mathrm{Am}^{-1}$. In this example, the total-field anomaly 


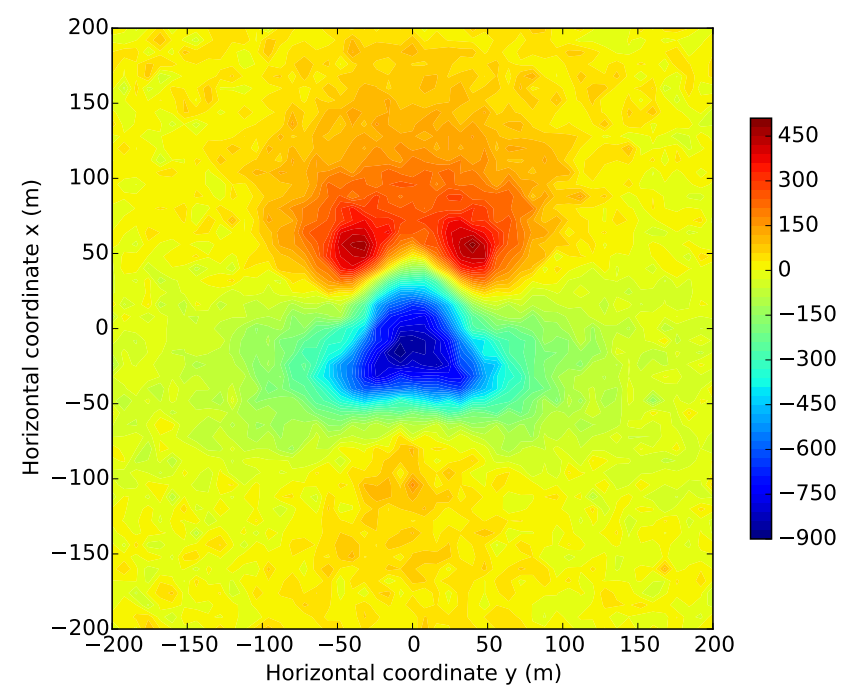

Figure 9. Strongly interfering anomalies. Noise-corrupted totalfield anomaly produced by the synthetic bodies shown in Fig. 8. The data are in $\mathrm{nT}$ and were calculated on a plane with a constant vertical coordinate equal to $-10 \mathrm{~m}$.

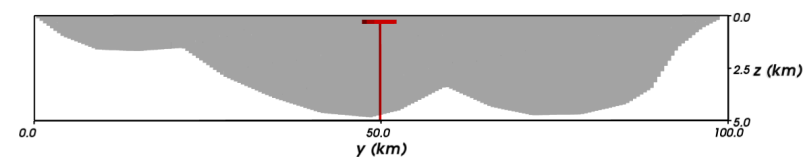

Figure 10. Igneous intrusion. 2-D schematic representation of a synthetic geologic setting composed of a non-magnetic sedimentary package (in grey), an igneous intrusion (in red) and a basement (in white). The sedimentary package and basement are semi-infinite along the $x$ axis. The basement is magnetized by induction and the intrusion has a strong reversed magnetization. The plot has vertical exaggeration.

produced by the intrusion overlaps the one produced by the basement. The total-field anomaly produced by both the intrusion and the basement was calculated on a $100 \times 100$ regular grid $(N=10000)$, which varies from 0 to $10 \mathrm{~km}$ and from 45 to $55 \mathrm{~km}$ in the $x$ and $y$ directions, respectively, on a plane with a constant vertical coordinate $-800 \mathrm{~m}$. Figure 11 shows this total-field anomaly contaminated with a pseudo-random Gaussian noise with zero mean and standard deviation equal to $2 \mathrm{nT}$.

We applied our method to the total-field anomaly shown in Fig. 11 that aimed to estimate the magnetization direction of the simulated intrusion (Fig. 10). The position of the synthetic intrusion was estimated by Euler deconvolution. The synthetic intrusion is not an ideal source and does not have a characteristic structural index. In this case, we (wrongly) presumed that the noise-corrupted total-field anomaly is produced by a spherical body, and use a structural index equal to 3. Figure 12 shows that the estimated location (black point) obtained by Euler deconvolution is placed outside the synthetic intrusion (red prisms). Even using this poor estimate

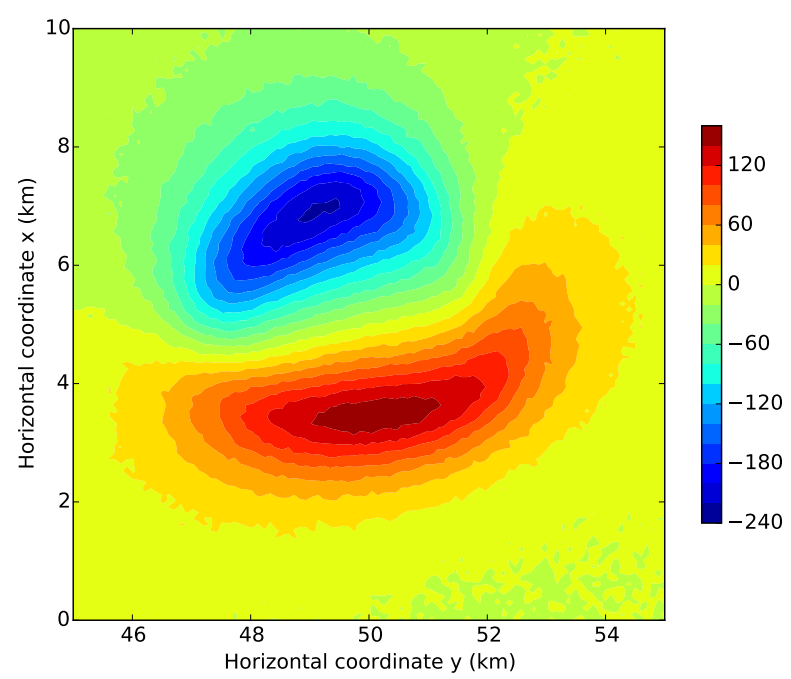

Figure 11. Igneous intrusion. Noise-corrupted total-field anomaly produced by the synthetic bodies shown schematically in Fig. 10. The data are in nT.

Table 3. Test with synthetic data (Fig. 9) showing strongly interfering anomalies. Comparison between the estimated and true values of the magnetization declination $D$ and inclination $I$. The uncertainties $\sigma_{\mathrm{D}}$ and $\sigma_{\mathrm{I}}$ (shown between parentheses) are calculated by using Eqs. (34) and (35). All values are in degrees $\left(^{\circ}\right)$. We use a caret $(\wedge)$ and a tilde $(\sim)$ to distinguish the quantities computed by using, respectively, the least-squares $\hat{\boldsymbol{h}}$ and robust $\widetilde{\boldsymbol{h}}$ estimates.

\begin{tabular}{llcrc}
\hline & Eastern prism & \multicolumn{3}{c}{ Western prism } \\
\hline$D$ & -23.41322 & - & 23.41322 & - \\
$\hat{D}$ & -31.45370 & $(0.00008)$ & 30.67233 & $(0.00875)$ \\
$\widetilde{D}$ & -26.57707 & $(0.01778)$ & 25.25037 & $(0.13333)$ \\
\hline$I$ & -7.54509 & - & -7.54509 & - \\
$\hat{I}$ & -9.23914 & $(0.00004)$ & -9.06131 & $(0.00628)$ \\
$\widetilde{I}$ & -7.98897 & $(0.00408)$ & -11.05456 & $(0.06386)$ \\
\hline
\end{tabular}

of the location of the source, our method obtained estimated declinations $(\hat{D}$ and $\widetilde{D})$ and inclinations $(\hat{I}$ and $\widetilde{I})$ close to the true values (Table 4$)$. In practical situations, however, the quality of the estimated magnetization direction may be accessed by using the reduction to the pole. Figure 13 shows that the reduction to the pole calculated with the robust estimate of the magnetization direction (Table 4) obtained by our method leads to a predominantly positive anomaly, which is very close to the true one. This result illustrates the robustness of our method when applied to retrieve the magnetization direction of a complex source whose centre is poorly estimated by Euler deconvolution. 


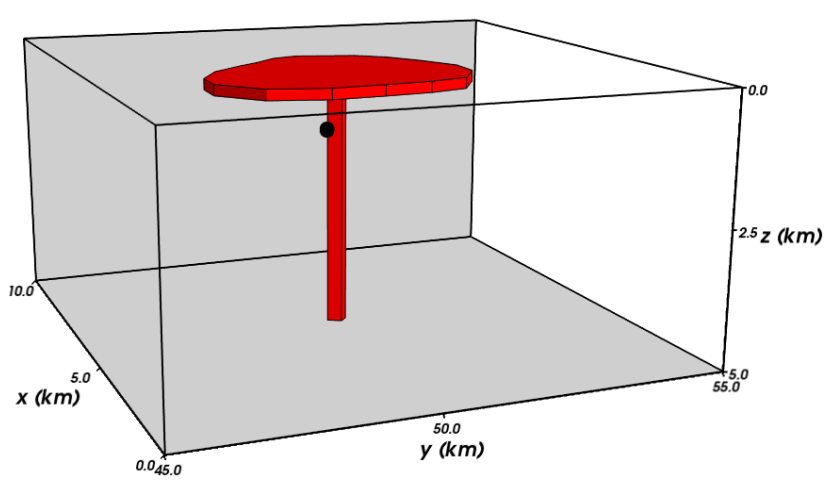

Figure 12. Igneous intrusion. 3-D view of the intrusion (red prisms) and the estimate of the intrusion position by using Euler deconvolution (black point) with a structural index equal to 3 . Notice that the Euler solution falls outside the intrusion.

Table 4. Test with synthetic data (Fig. 11) produced by a complex geological scenario. Comparison between the estimated and true values of the magnetization declination $D$ and inclination $I$. The uncertainties $\sigma_{\mathrm{D}}$ and $\sigma_{\mathrm{I}}$ (shown between parentheses) are calculated by using Eqs. (34) and (35). All values are in degrees $\left({ }^{\circ}\right)$. We use a caret $\left({ }^{\wedge}\right)$ and a tilde $\left({ }^{\sim}\right)$ to distinguish the quantities computed by using, respectively, the least-squares $\hat{\boldsymbol{h}}$ and robust $\widetilde{\boldsymbol{h}}$ estimates.

\begin{tabular}{ccc}
\hline \multicolumn{3}{c}{ Synthetic intrusion } \\
\hline$D$ & 157.50000 & - \\
$\hat{D}$ & 167.39501 & $(0.00060)$ \\
$\widetilde{D}$ & 164.19461 & $(0.02669)$ \\
\hline$I$ & 39.80000 & - \\
$\hat{I}$ & 37.33816 & $(0.00035)$ \\
$\widetilde{I}$ & 39.99470 & $(0.00939)$ \\
\hline
\end{tabular}

\section{Application to field data}

In Goiás state, central region of Brazil, there are occurrences of Cretaceous alkaline rocks along a lineament NW-SE that have been studied since the 60s. In a broad regional-scale study, Almeida (1983) denominated these occurrences as Rio Verde-Iporá Igneous Province. Posteriorly, Sgarbi and Gaspar (2002) grouped the Rio Verde-Iporá Igneous Province and the Alto Paranaíba Igneous Province (between the Goiás and Minas Gerais states, Fig. 14) into the Minas-Goiás alkaline province. According to these authors, the Minas-Goiás alkaline province would be divided into four sub-provinces: Mata da Corda, Alto do Paranaíba, Iporá and Santo Antônio da Barra. In the same year, Junqueira-Brod et al. (2002) returned to the concept of two distinct provinces. These authors maintained the old name Alto Paranaíba Igneous Province for designating the alkaline rocks located between the Goiás and Minas Gerais states and denominated the alkaline rocks near to Rio Verde and Iporá (in the Goiás state) as Goiás al-
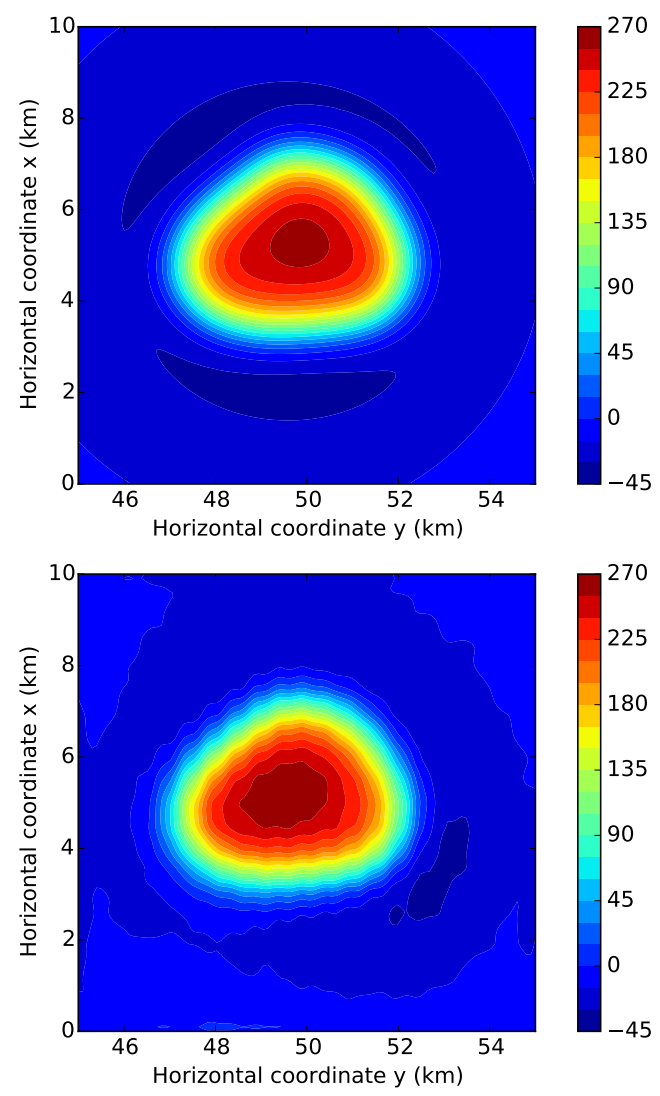

Figure 13. Igneous intrusion. The upper panel shows the true reduced-to-the-pole anomaly produced by the synthetic bodies shown in Fig. 10. The lower panel shows the reduced-to-the-pole anomaly obtained from the noise-corrupted total-field anomaly shown in Fig. 11. These anomalies were calculated at the same points of the total-field anomaly shown in Fig. 11. The reduction to the pole was calculated by using the robust estimates of declination $\widetilde{D}$ and inclination $\widetilde{I}$ shown in Table 4 .

kaline province (GAP). Here, we use this nomenclature proposed by Junqueira-Brod et al. (2002).

The GAP is formed by mafic to ultramafic alkaline rocks presenting a wide variety of petrographic types (Almeida, 1983; Junqueira-Brod et al., 2005; Carlson et al., 2007; Marangoni and Mantovani, 2013). Among the main alkaline complexes in the northern portion of GAP are the Montes Claros de Goiás, Diorama, Córrego dos Bois, Morro do Macaco and Fazenda Buriti (Fig. 14). These alkaline intrusions are surrounded by a Precambrian basement and the Phanerozoic sedimentary rocks of the Paraná basin. In 2004, this region was flown by an aeromagnetic survey at an approximately constant height of $100 \mathrm{~m}$ from the terrain (approximately constant normal height of $500 \mathrm{~m}$ ). This survey has a flight pattern with $\mathrm{N}-\mathrm{S}$ lines spaced from $500 \mathrm{~m}$ and E$\mathrm{W}$ tie-lines spaced from $5000 \mathrm{~m}$. Along each line, the data are spaced from approximately $8 \mathrm{~m}$. The data were corrected for diurnal variation and subtracted from the geomagnetic field 


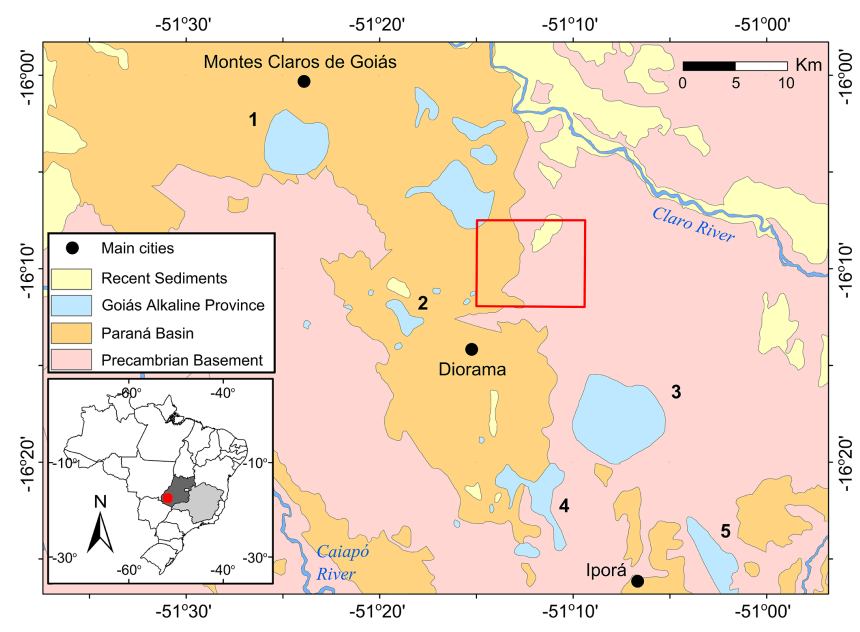

Figure 14. Application to field data on the Goiás alkaline province (GAP), Brazil. Simplified geological map of the study area, which is shown as a red dot on the inset map of Brazil. The inset also shows the Goiás (dark grey area) and Minas Gerais (light grey area) states. The total-field anomaly over the area delimited by the red rectangle is shown in Fig. 15. The coordinates are referred to as the WGS84 datum. The numbers indicate the main alkaline complexes in this region: 1 - Montes Claros de Goiás; 2 - Diorama; 3 - Córrego dos Bois; 4 - Morro do Macaco; and 5 - Fazenda Buriti.

modelled by using the International Geomagnetic Reference Field (IGRF) evaluated at the 2004.62 epoch, with declination $-18.5^{\circ}$ and inclination $-19.5^{\circ}$. This region is characterized by intense total-field anomalies (with notable remnant magnetization) that are generally associated with the alkaline rocks of the GAP (Dutra and Marangoni, 2009; Dutra et al., 2012; Marangoni and Mantovani, 2013).

We applied our method to interpret the data located in the area delimited by the red rectangle shown in Fig. 14, near to the alkaline complex of Diorama. The data are shown in Fig. 15. To attenuate the non-dipolar effects present in the data, we applied the polynomial equivalent layer (Oliveira Jr. et al., 2013) to continue the anomaly upward to a constant normal height of $1000 \mathrm{~m}$ on a regularly spaced grid. By inverting the upward continued data (not shown), we estimated the centre of the body by applying the Euler deconvolution and obtained its magnetization direction by using least-squares and robust estimates. We obtained the estimated inclinations $\hat{I}=-69.25595^{\circ} \pm 0.00013^{\circ}$ and $\widetilde{I}=$ $-71.41751^{\circ} \pm 0.00182^{\circ}$ and declinations $\hat{D}=-16.22821^{\circ} \pm$ $0.00050^{\circ}$ and $\widetilde{\widetilde{D}}=-23.39541^{\circ} \pm 0.01049^{\circ}$. The caret $\left(^{\wedge}\right)$ and tilde $(\sim)$ denote the results computed by using, respectively, the least-squares and robust estimates.

For verifying the plausibility of the estimated inclinations and declinations, we used them to reduce the observed total-field anomaly (Fig. 15) to the pole. Figure 16 shows that the estimated magnetization directions obtained with the least-squares and robust estimates lead to very confident RTP anomalies, since the dipolar characteristic of the

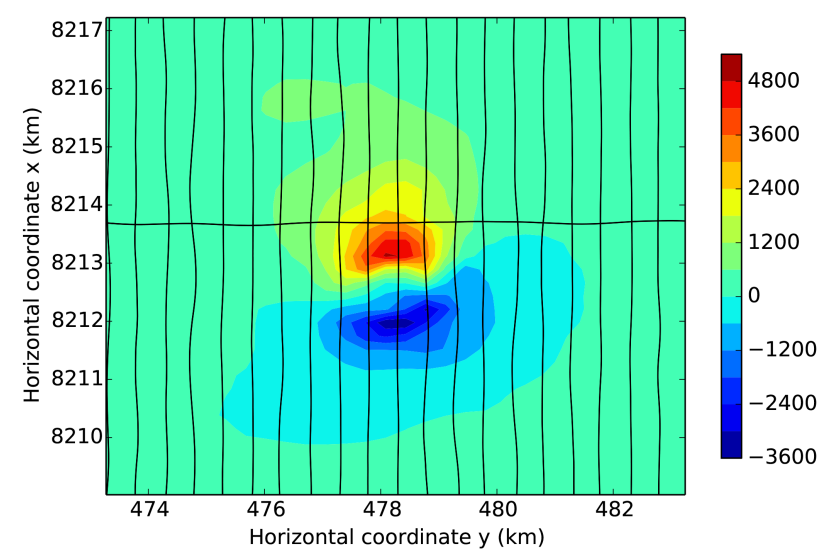

Figure 15. Application to field data on the Goiás alkaline province (GAP), Brazil. Total-field anomaly observed over the area delimited by the red rectangle in Fig. 14. The flight lines of the aeromagnetic survey are shown in black. The magnetic data are in nT and the coordinates are in UTM on the SAD-69 datum, with central meridian $51^{\circ} \mathrm{W}$. The origins of the eastern and northern coordinates are 500 and $10000 \mathrm{~km}$, respectively.
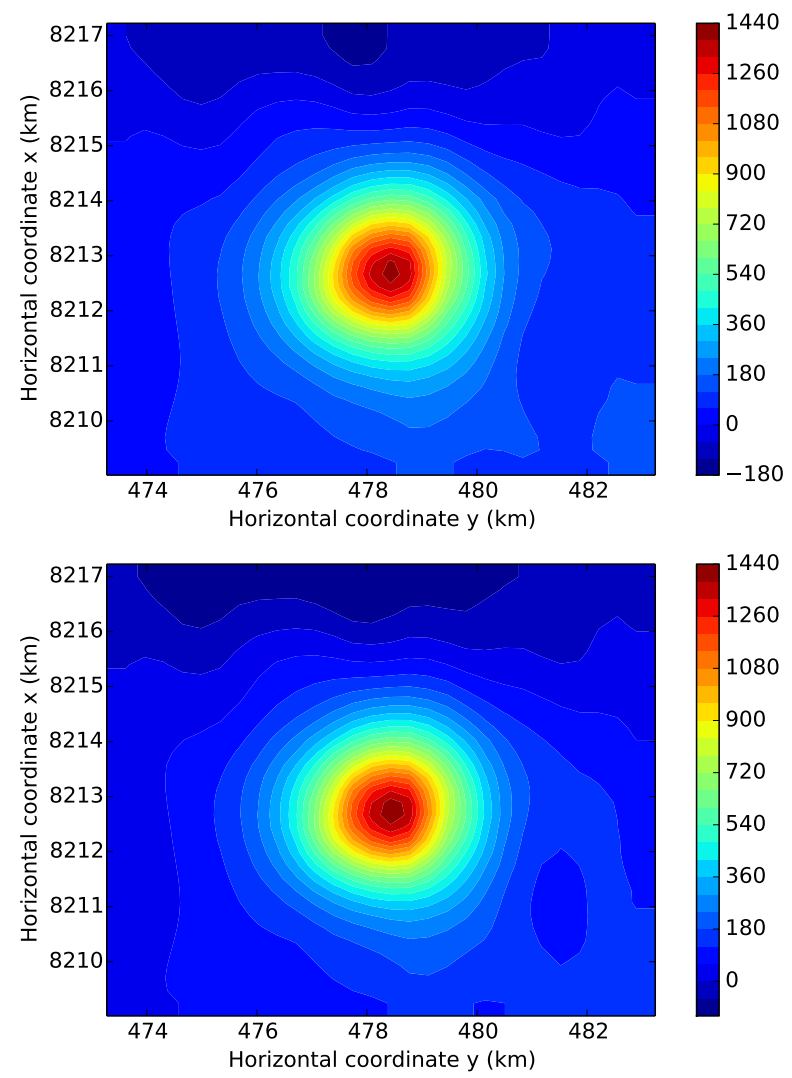

Figure 16. Application to field data on the Goiás alkaline province (GAP), Brazil. Observed total-field anomaly (Fig. 15) reduced to the pole. The upper and lower panels show the RTP anomalies computed by using, respectively, the estimated magnetization direction obtained with the least-squares (inclination $\hat{I}=-69.25595^{\circ} \pm$ $0.00013^{\circ}$ and declination $\left.\hat{D}=-16.22821^{\circ} \pm 0.00050^{\circ}\right)$ and robust (inclination $\widetilde{I}=-71.41751^{\circ} \pm 0.00182^{\circ}$ and declination $\widetilde{D}=$ $\left.-23.39541^{\circ} \pm 0.01049^{\circ}\right)$ estimates. 


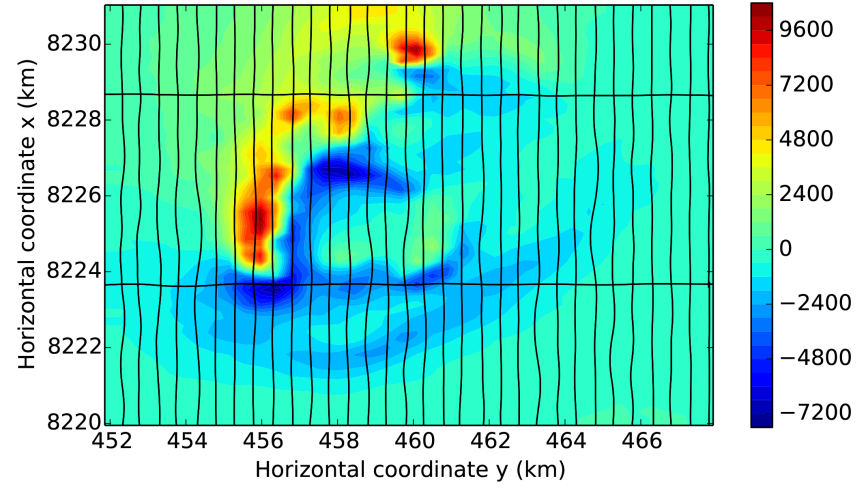

Figure 17. Application to field data on the Goiás alkaline province (GAP), Brazil. Total-field anomaly observed over the Montes Claros de Goiás alkaline complex (Fig. 14). The flight lines of the aeromagnetic survey are shown in black. The magnetic data are in nT and the coordinates are in UTM on the SAD-69 datum, with central meridian $51^{\circ} \mathrm{W}$. The origins of the eastern and northern coordinates are 500 and $10000 \mathrm{~km}$, respectively.

observed total-field anomaly (Fig. 15) is almost completely suppressed.

By using the estimated magnetization directions obtained from the simple dipolar total-field anomaly shown in Fig. 15, we reduced to the pole another complex non-dipolar totalfield anomaly (Fig. 17). This total-field anomaly is located over the Montes Claros de Goiás alkaline complex (Fig. 14), which is near to the alkaline complex of Diorama. Figure 18 shows that these estimated magnetization directions are very good because they yield predominantly positive RTP anomalies. These results show that the magnetization directions of the sources in the alkaline complex of Montes Claros de Goiás are very close to those ones estimated from the totalfield anomaly (Fig. 15) near to the alkaline complex of Diorama, suggesting that these sources emplaced at depth within almost the same geological time interval. Notice that, in this field-data application, the result obtained from inverting a small piece of the data set shed a light on this complex geological setting.

\section{Conclusions}

We present a computationally effective method for estimating the magnetization direction of multiple sources with approximately spherical shapes by inverting the total-field anomaly produced by them. Our method assumes that the sources have uniform magnetization and that the positions of their centres are known. Prior knowledge about the source sizes is not required. Our method can be applied for determining the average magnetization direction within multiple sources with different magnetization directions. Besides, it can be directly applied to interpret irregularly spaced totalfield anomaly data measured on uneven surfaces and requires
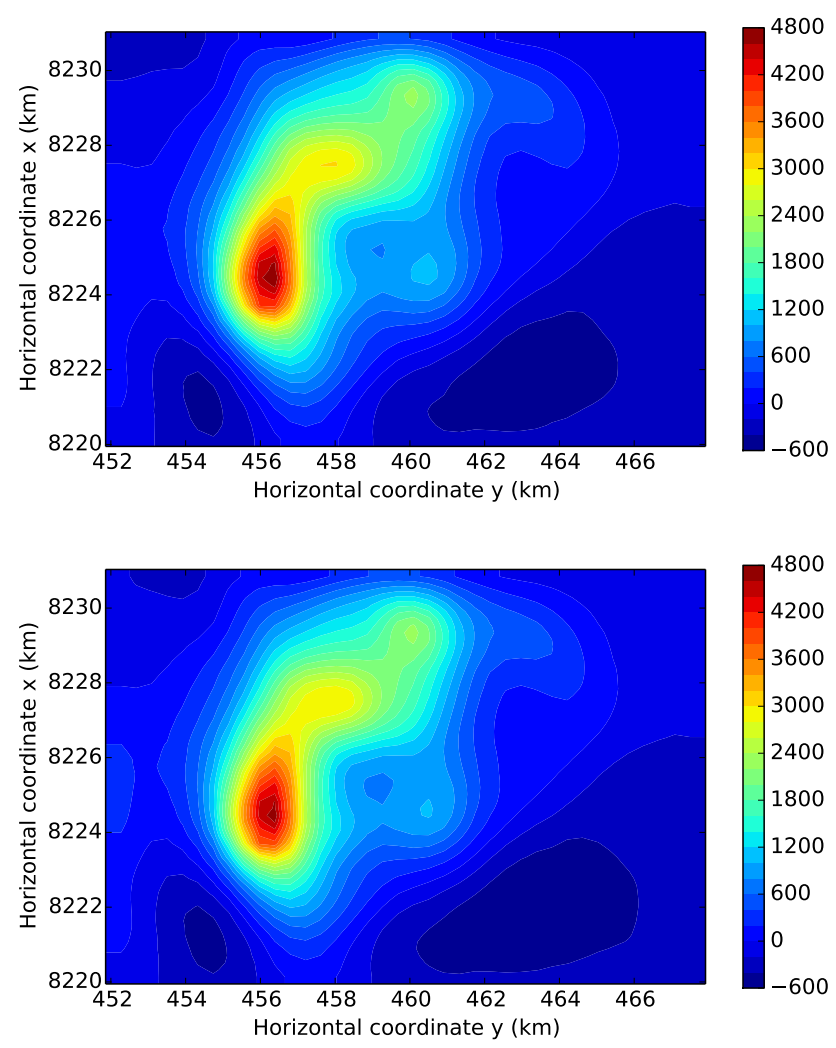

Figure 18. Application to field data on the Goiás alkaline province (GAP), Brazil. Observed total-field anomaly (Fig. 17) reduced to the pole. The upper and lower panels show the RTP anomalies computed by using, respectively, the estimated magnetization direction obtained with the least-squares (inclination $\hat{I}=-69.25595^{\circ} \pm$ $0.00013^{\circ}$ and declination $\left.\hat{D}=-16.22821^{\circ} \pm 0.00050^{\circ}\right)$ and robust (inclination $\widetilde{I}=-71.41751^{\circ} \pm 0.00182^{\circ}$ and declination $\widetilde{D}=$ $\left.-23.39541^{\circ} \pm 0.01049^{\circ}\right)$ estimates.

no prior transformation like reduction to the pole, total gradient or total magnitude anomalies. The method also contains flexibility to be implemented in two different numerical approaches. The first one is based on the minimization of the L2-norm of the residuals between the observed and predicted total-field anomalies. This approach results in a linear inverse problem for obtaining a least-squares estimate of the magnetization vector components of the sources. The second approach is based on the minimization of the L1-norm of the residuals between the observed and predicted totalfield anomalies, leading to a non-linear inverse problem for obtaining a robust estimate of the magnetization vector components of the sources.

The results obtained with the synthetic data simulating a spherical source with a known centre show the good performance of our method in retrieving the true magnetization direction. Tests with synthetic data produced by simulated sources that violate the premises assumed by our method show the robustness of our method against interfering anomalies and against errors in the location of the cen- 
tre of the source. The results show that our method is sensitive to errors in the horizontal location of the centre of the source. On the other hand, it is insensitive to errors in the depth of the centre of the source. Additionally, we show how the upward continuation can be used to make possible the application of our method for interpreting non-spherical sources producing total-field anomalies with non-dipolar features. These non-dipolar features can greatly affect the results obtained with the least-squares estimate, especially when the data are near to the source. Applications to field data over the Goiás alkaline province (GAP), Brazil, show that our method can be a powerful tool for interpreting real geological scenarios. Our estimates near to the alkaline complex of Diorama suggest the presence of non-outcropping sources with strong remanent magnetization, corroborating previous works. This estimated magnetization direction leads to very plausible RTP anomalies not only over the region near to the complex of Diorama, but also over the alkaline complex of Montes Claros de Goiás. These results show that the nonoutcropping sources near to the alkaline complex of Diorama have almost the same magnetization direction of those ones in the alkaline complex of Montes Claros de Goiás, strongly suggesting that these sources have emplaced at depth within almost the same geological time interval.

Although the upward continuation seems to be useful for overcoming the difficulties in the interpretation of strongly non-dipolar total-field anomalies, there will always be a limit for using this technique. The interpreter should always verify the quality of the estimated magnetization direction by using, for example, a reduction to the pole. One might think that the high sensitivity of our method to uncertainties in the horizontal coordinates of the centres of the sources is a drawback. This is not true because these coordinates are generally well estimated by the Euler deconvolution. The high sensitivity of our method to errors in horizontal locations of the centres of the sources suggests that the horizontal coordinates of the sources' centres could also be estimated by inversion. On the other hand, the insensitivity of our method to errors in the depth of the sources suggests that the sources' depth could not easily be estimated by inversion and would need some a priori information.

Acknowledgements. The authors would like to thank the Editor and the referees for their constructive review. The authors would also like to thank the government of the state of Goiás, Brazil, for permission to use the real aeromagnetic data set. D. P. Sales is particularly grateful to CPRM for permission to work in this research. V. C. F. Barbosa was supported by a fellowship from CNPq (Conselho Nacional de Desenvolvimento e Tecnológico) and L. Uieda was supported by a scholarship from CAPES (Coordenação de Aperfeiçoamento de Pessoal de Nível Superior). Additional support for the authors was provided by FAPERJ (Fundação Carlos Chagas Filho de Amparo à Pesquisa do Estado do Rio de Janeiro) under contracts E-26/103.175/2011 and E-26/111.152/2014 and CNPq under contract 445752/2014-9.
Edited by: R. Gloaguen

Reviewed by: J. Ebbing, P. G. Lelièvre, and one anonymous referee

\section{References}

Almeida, F. F. M.: Relações tectônicas das rochas alcalinas mesozóicas da região meridional da plataforma sul-americana, Revista Brasileira de Geociências, 13, 139-158, 1983 (in Brazilian Portuguese).

Aster, R. C., Borchers, B., and Thurber, C. H.: Parameter Estimation and Inverse Problems (International Geophysics), Academic Press, San Diego, USA, 2005.

Baranov, V.: A new method for interpretation of aeromagnetic maps: Pseudo-gravimetric anomalies, Geophysics, 22, 359-382, doi:10.1190/1.1438369, 1957.

Baranov, V. and Naudy, H.: Numerical calculation of the formula of reduction to the magnetic pole, Geophysics, 29, 67-79, doi:10.1190/1.1439334, 1964.

Barbosa, V. C. F. and Silva, J. B. C.: Interactive 2D magnetic inversion: A tool for aiding forward modeling and testing geologic hypotheses, Geophysics, 71, L43-L50, doi:10.1190/1.2258093, 2006.

Bard, Y.: Nonlinear Parameter Estimation, Academic Press, New York, USA, 1973.

Bhattacharyya, B. K.: A method for computing the total magnetization vector and the dimensions of a rectangular blockshaped body from magnetic anomalies, Geophysics, 31, 74-96, doi:10.1190/1.1439765, 1966.

Blakely, R. J.: Potential Theory in Gravity and Magnetic Applications, Cambridge University Press, Cambridge, UK, 1996.

Carlson, R. W., Araujo, A. L. N., Junqueira-Brod, T. C., Gaspar, J. C., Brod, J. A., Petrinovic, I. A., Hollanda, M. H. B., Pimentel, M. M., and Sichel, S.: Chemical and isotopic relationships between peridotite xenoliths and mafic-ultrapotassic rocks from Southern Brazil, Chem. Geol., 242, 415-434, doi:10.1016/j.chemgeo.2007.04.009, 2007.

Clark, D. A.: Methods for determining remanent and total magnetisations of magnetic sources - a review, Explor. Geophys., 45, 271-304, doi:10.1071/EG14013, 2014.

Dannemiller, N. and Li, Y.: A new method for determination of magnetization direction, Geophysics, 71, L69-L73, doi:10.1190/1.2356116, 2006.

Dutra, A. C. and Marangoni, Y. R.: Gravity and magnetic 3D inversion of Morro do Engenho complex, Central Brazil, J. S. Am. Earth Sci., 28, 193-203, doi:10.1016/j.jsames.2009.02.006, 2009.

Dutra, A. C., Marangoni, Y. R., and Junqueira-Brod, T. C.: Investigation of the Goiás Alkaline Province, Central Brazil: Application of gravity and magnetic methods, J. S. Am. Earth Sci., 33, 43-55, doi:10.1016/j.jsames.2011.06.004, 2012.

Ellis, R. G., de Wet, B., and Macleod, I. N.: Inversion of magnetic data for remanent and induced sources, ASEG Extended Abstracts, 1-4, doi:10.1071/ASEG2012ab117, 2012.

Emilia, D. and Massey, R.: Magnetization estimation for nonuniformly magnetized seamounts, Geophysics, 39, 223-231, doi:10.1190/1.1440423, 1974. 
Farquharson, C. G. and Oldenburg, D. W.: Non-linear inversion using general measures of data misfit and model structure, Geophys. J. Int., 134, 213-227, doi:10.1046/j.1365246x.1998.00555.x, 1998.

Fedi, M., Florio, G., and Rapolla, A.: A method to estimate the total magnetization direction from a distortion analysis of magnetic anomalies, Geophys. Prospect., 42, 261-274, doi:10.1111/j.1365-2478.1994.tb00209.x, 1994.

Fornasini, P.: The Uncertainty in Physical Measurements: An Introduction to Data Analysis in the Physics Laboratory, SpringerVerlag, New York, USA, 2008.

Gerovska, D., Araúzo-Bravo, M. J., and Stavrev, P.: Estimating the magnetization direction of sources from southeast Bulgaria through correlation between reduced-to-the-pole and total magnitude anomalies, Geophys. Prospect., 57, 491-505, doi:10.1111/j.1365-2478.2008.00761.x, 2009.

Helbig, K.: Some integrals of magnetic anomalies and their relation to the parameters of the disturbing body, Zeitschrift fur Geophysik, 29, 83-96, 1963.

Hunter, J. D.: Matplotlib: A 2D graphics environment, Comput. Sci. Eng., 9, 90-95, doi:10.1109/MCSE.2007.55, 2007.

Junqueira-Brod, T. C., Roig, H. L., Gaspar, J. C., Brod, J. A., and Meneses, P. R.: A Província Alcalina de Goiás e a extensão do seu vulcanismo kamafugítico, Revista Brasileira de Geociências, 32, 559-566, 2002.

Junqueira-Brod, T. C., Gaspar, J. C., Brod, J. A., and Kafino, C. V.: Kamafugitic diatremes: their textures and field relationships with examples from the Goiás alkaline province, Brazil, J. S. Am. Earth Sci., 18, 337-353, doi:10.1016/j.jsames.2004.11.002, 2005.

Kubota, R. and Uchiyama, A.: Three-dimensional magnetization vector inversion of a seamount, Earth Planets Space, 57, 691699, doi:10.1186/BF03351849, 2005.

Langel, R. A. and Hinze, W. J.: The Magnetic Field of the Earth's Lithosphere: The Satellite Perspective, Cambridge University Press, Cambridge, UK, 1998.

Lelièvre, P. G. and Oldenburg, D. W.: A 3D total magnetization inversion applicable when significant, complicated remanence is present, Geophysics, 74, L21-L30, doi:10.1190/1.3103249, 2009.

Li, X.: Understanding 3D analytic signal amplitude, Geophysics, 71, L13-L16, doi:10.1190/1.2184367, 2006.

Li, Y. and Oldenburg, D. W.: 3-D inversion of magnetic data, Geophysics, 61, 394-408, doi:10.1190/1.1443968, 1996.

Marangoni, Y. R. and Mantovani, M. S.: Geophysical signatures of the alkaline intrusions bordering the Paraná Basin, J. S. Am. Earth Sci., 41, 83-98, doi:10.1016/j.jsames.2012.08.004, 2013.

Medeiros, W. E. and Silva, J. B. C.: Simultaneous estimation of total magnetization direction and 3-D spatial orientation, Geophysics, 60, 1365-1377, doi:10.1190/1.1443872, 1995.

Melo, F., Barbosa, V., Uieda, L., Oliveira Jr., V., and Silva, J.: Estimating the nature and the horizontal and vertical positions of 3D magnetic sources using Euler deconvolution, Geophysics, 78, J87-J98, doi:10.1190/geo2012-0515.1, 2013.

Menke, W.: Geophysical Data Analysis: Discrete Inverse Theory (International Geophysics), Academic Press, San Diego, USA, 1989.

Nabighian, M.: The analytic signal of two-dimensional magnetic bodies with polygonal cross-section: its properties and use for automated anomaly interpretation, Geophysics, 37, 507-517, doi:10.1190/1.1440276, 1972.

Nabighian, M.: Additional comments on the analytic signal of twodimensional magnetic bodies with polygonal cross-section, Geophysics, 39, 85-92, doi:10.1190/1.1440416, 1974.

Nabighian, M.: Toward a three-dimensional automatic interpretation of potential field data via generalized Hilbert transforms: Fundamental relations, Geophysics, 49, 780-786, doi:10.1190/1.1441706, 1984.

Nabighian, M., Grauch, V., Hansen, R., LaFehr, T., Li, Y., Peirce, J., Phillips, J., and Ruder, M.: The historical development of the magnetic method in exploration, Geophysics, 70, 33ND-61ND, doi:10.1190/1.2133784, 2005.

Oliveira Jr., V. C., Barbosa, V. C. F., and Uieda, L.: Polynomial equivalent layer, Geophysics, 78, G1-G13, doi:10.1190/geo2012-0196.1, 2013.

Parker, R. L., Shure, L., and Hildebrand, J. A.: The application of inverse theory to seamount magnetism, Rev. Geophys., 25, 1740, doi:10.1029/RG025i001p00017, 1987.

Pérez, F. and Granger, B. E.: IPython: a System for Interactive Scientific Computing, Comput. Sci. Eng., 9, 21-29, doi:10.1109/MCSE.2007.53, 2007.

Phillips, J. D.: Can we estimate total magnetization directions from aeromagnetic data using Helbig's integrals?, Earth Planets Space, 57, 681-689, 2005.

Pilkington, M.: 3-D magnetic imaging using conjugate gradients, Geophysics, 62, 1132-1142, doi:10.1190/1.1444214, 1997.

Portniaguine, O. and Zhdanov, M. S.: Focusing geophysical inversion images, Geophysics, 64, 874-887, doi:10.1190/1.1444596, 1999.

Portniaguine, O. and Zhdanov, M. S.: 3-D magnetic inversion with data compression and image focusing, Geophysics, 67, 15321541, doi:10.1190/1.1512749, 2002.

Ramachandran, P. and Varoquaux, G.: Mayavi: 3D visualization of scientific data, Comput. Sci. Eng., 13, 40-51, doi:10.1109/MCSE.2011.35, 2011.

Reid, A., Allsop, J., Granser, H., Millett, A., and Somerton, I.: Magnetic interpretation in three dimensions using Euler deconvolution, Geophysics, 55, 80-91, doi:10.1190/1.1442774, 1990.

Reid, A. B., Ebbing, J., and Webb, S. J.: Avoidable Euler Errors - the use and abuse of Euler deconvolution applied to potential fields, Geophys. Prospect., 62, 1162-1168, doi:10.1111/13652478.12119, 2014.

Roest, W. R. and Pilkington, M.: Identifying remanent magnetization effects in magnetic data, Geophysics, 58, 653-659, doi:10.1190/1.1443449, 1993.

Scales, J. A., Gerztenkorn, A., and Treitel, S.: Fast $l_{p}$ solution of large, sparse, linear systems: Application to seismic travel time tomography, J. Comput. Phys., 75, 314-333, doi:10.1016/00219991(88)90115-5, 1988.

Sgarbi, P. B. A. and Gaspar, J. C.: Geochemistry of Santo Antônio da Barra Kamafugites, Goiás, Brazil, J. S. Am. Earth Sci., 14, 889-901, doi:10.1016/S0895-9811(01)00079-7, 2002.

Silva, J. B. C.: Reduction to the pole as an inverse problem and its application to low-latitude anomalies, Geophysics, 51, 369-382, doi:10.1190/1.1442096, 1986.

Silva, J. B. C. and Barbosa, V.: 3D Euler deconvolution: Theoretical basis for automatically selecting good solutions, Geophysics, 68, 1962-1968, doi:10.1190/1.1635050, 2003. 
Telford, W. M., Geldart, L. P., and Sheriff, R. E.: Applied Geophysics, Cambridge University Press, Cambridge, UK, 1990.

Thompson, D.: EULDPH: A new technique for making computerassisted depth estimates from magnetic data, Geophysics, 47, 31-37, doi:10.1190/1.1441278, 1982.

Tontini, F. C. and Pedersen, L. B.: Interpreting magnetic data by integral moments, Geophys. J. Int., 174, 815-824, doi:10.1111/j.1365-246X.2008.03872.x, 2008.
Twomey, S.: Introduction to the Mathematics of Inversion in Remote Sensing and Indirect Measurements, Dover Publications, Inc., Mineola, USA, 1977.

Uieda, L., Oliveira Jr., V. C., and Barbosa, V. C. F.: Geophysical tutorial: Euler deconvolution of potential-field data, The Leading Edge, 33, 448-450, doi:10.1190/tle33040448.1, 2014. 